\title{
Efficacy, safety, and tolerability of abatacept in the management of rheumatoid arthritis
}

This article was published in the following Dove Press journal:

Open Access Rheumatology Research and Reviews

8 May 2009

Number of times this article has been viewed

Joseph R Lutt

Division of Arthritis and Rheumatic Diseases, Oregon Health and Science University, Portland, Oregon, USA
Correspondence: Joseph R Lutt Division of Arthritis and Rheumatic Diseases, Oregon Health and Science University, Portland, Oregon, USA

Email luttj@ohsu.edu

\begin{abstract}
The management of rheumatoid arthritis (RA) has undergone an impressive transformation over the past few decades. Further understanding of the pathophysiology of the disease process has resulted in the development of biologic agents that target proinflammatory cytokines and both B and T lymphocytes. By blocking an important costimulatory pathway, abatacept leads to a dramatic reduction in T cell stimulation and proliferation. Multiple clinical trials have revealed consistent benefit with regards to clinical and radiographic efficacy, quality of life, and disability in patients suffering from RA who have had inadequate responses to methotrexate or tumor necrosis factor inhibitors. The possibility of remission when used early in the disease course has also been demonstrated. Importantly, abatacept has been very well tolerated with a low rate of serious infections and no apparent increase in malignancies to date. Continued surveillance of the benefits and risks will help to better define its place amongst the other biologic agents in the treatment of RA.
\end{abstract}

Keywords: abatacept, rheumatoid arthritis, infliximab, etanercept, adalimumab, rituximab, disease-modifying antirheumatic drug

\section{Introduction to rheumatoid arthritis and the approach to therapy}

Rheumatoid arthritis (RA) is a chronic, inflammatory, polyarthritis affecting approximately $1 \%$ of adults worldwide. ${ }^{1,2}$ With inadequate treatment, the disease can result in progressive joint damage and disability. ${ }^{3}$ The initiation of early therapy with one or more disease-modifying antirheumatic drugs (DMARDs) often leads to clinical improvement in pain, stiffness, and swelling and also slows the progression of structural damage. ${ }^{4,5}$ Studies have revealed that it is actually possible to achieve a state of disease remission, and this has become the goal in the treatment of RA. ${ }^{6}$ When DMARDs are started later in the disease course, the prospect of achieving a good response or remission is lower. ${ }^{7,8}$ With this knowledge, rheumatologists have become more aggressive in the management of RA in an attempt to halt ongoing inflammation as soon as possible with the hope of not only improving quality of life and function but also preventing structural damage and long-term disability.

The response to the available nonbiologic DMARDs is variable, and patients often require additional therapy. Methotrexate (MTX), the "anchor drug" of initial treatment, ${ }^{6}$ can achieve a state of clinical remission in approximately $20 \%$ to $30 \%$ of patients when used as monotherapy in early RA but uncommonly in established or advanced disease. ${ }^{9-12}$ Switching from an oral to subcutaneous route of MTX 
administration, ${ }^{13}$ adding additional oral agents including glucocorticoids, ${ }^{14-17}$ or switching to or adding leflunomide ${ }^{18,19}$ may increase the response rate somewhat, but it has become apparent that many patients will eventually require the addition of a biologic DMARD in order to achieve a state of clinical remission and cessation of radiographic progression. The use of these agents has had a dramatic effect on the care of patients with RA and has made remission a realistic goal, especially when started early in the disease course.

The cytokines interleukin-1 (IL-1) and tumor necrosis factor (TNF) are detected in synovial fluid of patients with RA and are prominent inflammatory mediators in the disease process. ${ }^{20}$ Anakinra is an IL-1 receptor antagonist that is effective in treating $\mathrm{RA}^{21-24}$ but is used infrequently due to the need for daily self-injections and, although no head-to-head studies exist, the perception of inferiority compared with the other biologic agents. ${ }^{25,26}$ Etanercept, infliximab, and adalimumab, which inhibit the action of TNF, are approved by the US Food and Drug Administration (FDA) for the treatment of RA refractory to one or more DMARDs. These agents have consistently improved the clinical and radiographic manifestations of RA. ${ }^{27-30}$ Unfortunately, about one-third of patients will discontinue one of these agents within 12 months due to a lack of efficacy or an adverse event, ${ }^{31,32}$ and only $40 \%$ to $60 \%$ of patients improve by at least $50 \%{ }^{33}$ As reviewed previously, the options for the management of these patients include switching to a different TNF inhibitor (TNFI) or substituting one of the newer biologic agents, rituximab or abatacept. ${ }^{34}$

By targeting cells expressing CD20, rituximab effectively depletes peripheral B cells and has been approved for use in combination with MTX for moderately to severely active RA after an inadequate response to at least one TNFI. It is a chimeric monoclonal antibody that is given as a series of 2 intravenous (iv) infusions 2 weeks apart approximately every 6 months. It has proven efficacious with regards to both the clinical and radiographic manifestations of the disease. ${ }^{35-38}$

Abatacept was approved by the FDA in 2005 for the treatment of moderate or severe RA despite an adequate trial of a nonbiologic or biologic DMARD. The European Medicines Agency (EMEA) approved its use only after an inadequate response or intolerance to a TNFI. By blocking an important costimulatory pathway it prevents $T$ cell activation and has demonstrated reliable efficacy and tolerability for patients with refractory disease. This review will focus on the mechanism, pharmacology, efficacy, and safety of abatacept and summarize its role in the management of adult patients with RA.

A Medline search was performed with combinations of the terms "rheumatoid arthritis," "abatacept," "rituximab," "etanercept," "adalimumab," and "infliximab." Additionally, the reference sections from the articles obtained as well as abstracts from the American College of Rheumatology (ACR) and European League Against Rheumatism (EULAR) annual meetings were scanned for pertinent references.

\section{Abatacept mechanism of action}

Optimal $\mathrm{T}$ cell activation requires two recognized steps. The first involves the presentation of a peptide by an MHC class II molecule on the surface of an activated antigen-presenting cell to a $\mathrm{T}$ cell that recognizes that particular peptide. The second step involves a costimulatory signal. The best characterized costimulatory pathway involves the interaction of CD80 and CD86 on the surface of an antigen-presenting cell with $\mathrm{CD} 28$ on the surface of most $\mathrm{CD} 4^{+}$and some $\mathrm{CD} 8^{+}$ $\mathrm{T}$ cells. When both steps occur, a naïve $\mathrm{T}$ cell can then become optimally activated to proliferate and efficiently produce cytokines. When an antigen is presented without a costimulatory signal, the $\mathrm{T}$ lymphocyte may become anergic and/or undergo apoptosis. ${ }^{39}$

Cytotoxic T-lymphocyte-associated antigen-4 (CTLA-4) is expressed on the surface of activated T cells. It is structurally homologous to CD28 but actually binds CD80 and CD86 with greater avidity than CD28. By doing so, CTLA-4 effectively blocks the engagement of CD80 and CD86 with CD28 and prevents costimulation and the activation of T lymphocytes. Thus, CTLA-4 acts as a natural down-regulator of $\mathrm{T}$ cell activation and avoids overstimulation in the presence of antigen.

Abatacept was developed by fusing the heavy-chain constant region of human $\mathrm{IgG1}$ with the extracellular domain of human CTLA-4. By binding CD80 and CD86 and preventing the interaction of those molecules with CD28 it has been shown to reduce $\mathrm{T}$ cell proliferation by at least $95 \%$ at concentrations lower than the mean trough levels of patients treated with abatacept. ${ }^{40}$ In doing so, this molecule has proven efficacious in animal models of autoimmunity ${ }^{41,42}$ and allograft rejection, ${ }^{43}$ juvenile idiopathic arthritis, ${ }^{44}$ and, as reviewed below, in reducing the clinical signs, slowing the progression of structural damage, and improving the quality of life and function of adult patients with RA. 


\section{Abatacept pharmacology and pharmacokinetics}

Abatacept is administered as an iv infusion over 30 minutes on days 1, 15, and 29 and then every 4 weeks thereafter. This is more frequent than the other infusible biologic agents, infliximab (every 8 weeks initially) and rituximab (approximately every 6 months), but the duration of each abatacept infusion is typically shorter. The dose is weightbased at approximately $10 \mathrm{mg} / \mathrm{kg}$ of the patient's body weight. Patients weighing less than $60 \mathrm{~kg}$ receive $500 \mathrm{mg}$, those between 60 and $100 \mathrm{~kg}$ receive $750 \mathrm{mg}$, and a dose of $1000 \mathrm{mg}$ is given to patients weighing over $100 \mathrm{~kg}$.

The mean serum half-life is 13 days, ${ }^{45}$ and serum concentrations reach a steady-state after approximately 60 days. ${ }^{46}$ Its clearance does not seem to be affected by sex and age, ${ }^{47}$ but the effect of renal or hepatic dysfunction on drug clearance is unknown. ${ }^{45,47}$

There have been no studies with abatacept during pregnancy. It is listed as a category $\mathrm{C}$ drug and should therefore be used only if the potential benefit to the mother outweighs the possible fetal risk. It does cross the placenta in animal studies but was not teratogenic in mice, rats, and rabbits at doses up to 29 times the maximum recommended human dose. ${ }^{46}$ When given to rats at 11 times the human dose alterations in immune function as well as thyroid and pancreas inflammation occurred in offspring. ${ }^{46}$ Abatacept is excreted in rat milk, but it is unknown whether the same is true with humans and whether it is absorbed by the nursing infant. ${ }^{46}$

\section{Abatacept in clinical trials}

In the RA trials involving abatacept (Table 1), multiple tools are used to assess and report outcomes regarding clinical and radiographic efficacy, quality of life, and physical function. The different methods are reviewed briefly below for readers not familiar with RA studies.

- Clinical efficacy is commonly reported by using the American College of Rheumatology (ACR) criteria which measure the proportion of patients achieving $20 \%$, $50 \%$, and $70 \%$ responses. $^{48,49}$ For example, an ACR 20 indicates $20 \%$ fewer tender and swollen joints as well as a $20 \%$ improvement of 3 of the following: patient's global assessment of disease status, patient's assessment of pain, patient's assessment of function, physician's global assessment of disease status, and either erythrocyte sedimentation rate or C-reactive protein (CRP).

- Disease activity states and improvements in disease activity often utilize the Disease Activity Score (DAS). ${ }^{50-52}$ The DAS28 signifies that 28 joints were used in the assessment. Low disease activity states (DAS28 < 3.2), a state of clinical remission (DAS28 <2.6), as well as an assessment of the degree of improvement can be defined using this scoring system.

Table I Baseline characteristics of patients in abatacept trials

\begin{tabular}{|c|c|c|c|c|c|c|c|}
\hline $\begin{array}{l}\text { Baseline } \\
\text { features }\end{array}$ & Phase ${I I l b^{a}}^{a}$ & ATTAIN ${ }^{b}$ & AIM $^{a}$ & ASSURE & $\begin{array}{l}\text { Phase Ilb } \\
\text { combination } \\
\text { therapy }\end{array}$ & ATTEST $^{\mathrm{a}}$ & AGREE ${ }^{\mathrm{a}}$ \\
\hline $\begin{array}{l}\text { Number of } \\
\text { patients per arm }\end{array}$ & $\begin{array}{l}105 \mathrm{ABA}^{\mathrm{c}} \\
115 \mathrm{ABA} \\
119 \mathrm{PBO}\end{array}$ & $\begin{array}{l}258 \text { ABA } \\
133 \text { PBO }\end{array}$ & $\begin{array}{l}433 \mathrm{ABA} \\
219 \mathrm{PBO}\end{array}$ & $\begin{array}{l}959 \mathrm{ABA}^{\mathrm{d}} \\
482 \mathrm{PBO}^{\mathrm{e}}\end{array}$ & $\begin{array}{l}85 \mathrm{ABA}^{c}+\mathrm{ETA} \\
36 \mathrm{PBO}+\mathrm{ETA}\end{array}$ & $\begin{array}{l}\text { I56 ABA } \\
\text { I } 65 \text { INF } \\
\text { I I0 PBO }\end{array}$ & $\begin{array}{l}256 \mathrm{ABA} \\
253 \mathrm{PBO}\end{array}$ \\
\hline $\begin{array}{l}\text { Prior therapy } \\
\text { (inclusion criteria) }\end{array}$ & $\begin{array}{l}\text { MTX for } \\
6 \text { months }\end{array}$ & $\begin{array}{l}\text { TNFI + oral } \\
\text { DMARD for } \\
3 \text { months }\end{array}$ & $\begin{array}{l}\text { MTX for } \\
3 \text { months }\end{array}$ & $\begin{array}{l}\text { Any DMARD for } \\
3 \text { months }\end{array}$ & $\begin{array}{l}\text { ETA for } \\
3 \text { months }\end{array}$ & $\begin{array}{l}\text { MTX for } \\
3 \text { months }\end{array}$ & MTX naïve \\
\hline $\begin{array}{l}\text { Prior biologic } \\
\text { exposure }\end{array}$ & $\begin{array}{l}2.6 \%-5.7 \% \\
\text { prior TNFI }\end{array}$ & All patients & $<1 \%$ & $\begin{array}{l}12 \% \text { with ongoing } \\
\text { biologic therapy }\end{array}$ & All patients & None & None \\
\hline Disease duration & 8.9-9.7 years & $11.4-12.2$ years & $8.5-8.9$ years & $9.5-11.3$ years & $12.8-13$ years & $7.3-8.4$ years & $6.2-6.7$ months \\
\hline Tender joints & $28.2-30.8$ & $31.2-32.8$ & $31.0-32.3$ & - & $28.7-29.2$ & $30.3-31.7$ & $30.8-31.3$ \\
\hline Swollen joints & $20.2-21.8$ & $22.0-22.3$ & $21.4-22.1$ & - & $19.6-20.1$ & $20.1-21.3$ & $21.9-22.9$ \\
\hline DAS28 & $5.4-5.5$ & 6.5 & $6.3-6.4$ & - & - & $6.8-6.9$ & $6.2-6.3$ \\
\hline
\end{tabular}

Notes: Unless otherwise noted, ABA $10 \mathrm{mg} / \mathrm{kg}$ every 4 weeks.

aall patients received concomitant MTX.

ball patients received concomitant nonbiologic DMARDs (MTX 75\%-80\%, sulfasalazine 7\%-10\%, hydroxychloroquine $9 \%$, leflunomide $8 \%-9 \%$ ).

cabatacept $2 \mathrm{mg} / \mathrm{kg}$ every 4 weeks.

d 03 of the 959 patients ( $10.7 \%$ ) received ABA plus a TNFI or anakinra.

e64 of the 482 patients (13.3\%) received PBO plus a TNFI or anakinra.

Abbreviations: ABA, abatacept; PBO, placebo; ETA, etanercept; INF, infliximab 3 mg/kg every 8 weeks; MTX, methotrexate; TNFI, tumor necrosis factor inhibitor; DMARD, disease-modifying antirheumatic drug; DAS, disease activity score. 
- Radiographic changes in the abatacept trials were reported with the Genant-modified Sharp scoring method, which provides a total score based upon assessment of joint space narrowing and the presence of erosions..$^{53,54}$

- The Short Form-36 (SF-36) is a questionnaire completed by patients to assess health-related quality of life by evaluating 8 different physical and mental components. ${ }^{55}$ The scale runs from 0 to 100 , with an increase of at least 3 points from baseline being a clinically important improvement. ${ }^{56,57}$

- Improvements in physical function can be measured using the Health Assessment Questionnaire-Disability Index (HAQ-DI), which is made up of 8 subscales of physical disability. ${ }^{58}$ On this scale, a score of 0 signifies no disability, and 3 means complete disability. An increase of at least 0.22 units is considered a clinically meaningful improvement.

\section{Abatacept efficacy and safety after an inadequate response to MTX Pilot study}

In 2002 Moreland et al reported a pilot study assessing the safety and efficacy of abatacept. ${ }^{59}$ Patients with active RA despite a trial of at least one oral DMARD or etanercept were randomized and treated in a blind fashion with placebo or various doses of abatacept. The study was not powered to detect differences between the groups, but the primary outcome of an ACR 20 response after 85 days was numerically greater in those who received $2 \mathrm{mg} / \mathrm{kg}$ and $10 \mathrm{mg} / \mathrm{kg}$ (but not $0.5 \mathrm{mg} / \mathrm{kg}$ ) of abatacept compared with placebo. Adverse event rates were similar with more arthritis flares in the placebo group and more headaches (8.9\% vs $3.1 \%)$ in the abatacept group.

\section{Phase Ilb trial}

A phase IIb trial was reported by Kremer et al in 2003. ${ }^{60}$ It was a double-blind, placebo-controlled study involving 339 patients with active RA despite taking MTX for at least 6 months. Patients were randomized to placebo, abatacept $2 \mathrm{mg} / \mathrm{kg}$, or abatacept $10 \mathrm{mg} / \mathrm{kg}$ for 12 months. All patients were also treated with a stable dose of MTX between 10 and $30 \mathrm{mg} /$ week through the first 180 days of the study. Thereafter, the MTX dose could be increased up to $30 \mathrm{mg} /$ week and additional DMARDs could be added based upon the judgment of the investigator. The primary outcome measure was an ACR 20 response after 180 days, with ACR 50 and 70 responses being the secondary outcomes.
The mean duration of disease ranged from 8.9 to 9.7 years and all patients had erosive disease at baseline. After 6 months ACR 20 responses were similar in the placebo and $2 \mathrm{mg} / \mathrm{kg}$ groups, but the $10 \mathrm{mg} / \mathrm{kg}$ group showed a statistically significant greater ACR 20 response rate compared with placebo $(60.0 \%$ vs $35.3 \%$, respectively ( $p<0.001)$ (Table 2$)$. ACR 50 and 70 responses were significantly higher in both abatacept groups. Patients who received $10 \mathrm{mg} / \mathrm{kg}$ also had clinically meaningful and statistically significant improvements in total SF-36 scores as well as each of the eight individual subscales. The greatest improvements were seen with regards to physical health, pain, vitality, and social function. The adverse event rates were similar among the groups, and there were no deaths or opportunistic infections during the first 6 months of this study (Table 3 ).

\section{Phase Ilb I-year extension study}

The 12-month findings were published by Kremer at al in 2005. ${ }^{61}$ For the data analysis, those who discontinued therapy due to lack of efficacy were considered nonresponders, and those who withdrew from the study for other reasons had their last observations carried forward.

At 12 months the greater ACR criteria responses with abatacept $10 \mathrm{mg} / \mathrm{kg}$ persisted (Table 2). There was no difference, however, between placebo and $2 \mathrm{mg} / \mathrm{kg}$ with regards to ACR 20, 50, or 70 responses indicating a lack of efficacy of this lower dose. The benefit in physical function in the $10 \mathrm{mg} / \mathrm{kg}$ group also remained greater through 12 months. Baseline modified HAQ (M-HAQ) scores were 1.0 in all groups. A significant improvement was already noted after 30 days, and after 12 months half of patients receiving $10 \mathrm{mg} / \mathrm{kg}$ achieved clinically important improvements compared with $28 \%$ in the placebo group $(\mathrm{p}<0.001)$. Approximately $16 \%$ of abatacept-treated patients reported an M-HAQ

Table 2 Efficacy of abatacept at 12 months after inadequate responses to $\mathrm{MTX}$

\begin{tabular}{lll}
\hline Outcome & Phase Ilb & AIM \\
\hline ACR 20 & $62.6(36.1)$ & $73.1(39.7)$ \\
ACR 50 & $41.7(20.2)$ & $48.3(18.2)$ \\
ACR 70 & $20.9(7.6)$ & $28.8(6.1)$ \\
LDAS & $49.6(21.9)$ & $42.5(9.9)$ \\
Remission & $34.8(10.1)$ & $23.8(1.9)$ \\
\hline
\end{tabular}

Notes: The percentage of patients obtaining a given outcome with abatacept is listed first followed by placebo in parentheses.

$\mathrm{P}<0.00$ I for all data from the phase Ilb trial and the ACR 20 and 50 responses and remission rates from AIM. $p<0.003$ for ACR 70 and $<0.05$ for LDAS in AIM.

Abbreviations: ACR,American College of Rheumatology; LDAS, low disease activity score (DAS28 < 3.2); Remission, DAS28 $<2.6$. 
Table 3 Adverse events during the trials' double-blind periods

\begin{tabular}{|c|c|c|c|c|c|c|c|c|}
\hline \multirow[t]{2}{*}{ Adverse event } & \multicolumn{2}{|l|}{ Ilb Trial ${ }^{a}$} & \multicolumn{2}{|l|}{ ATTAIN $^{b}$} & \multicolumn{2}{|l|}{ AIM $^{a}$} & \multicolumn{2}{|c|}{ ASSUREc } \\
\hline & $\begin{array}{l}\text { Placebo } \\
\text { n, I I9 }\end{array}$ & $\begin{array}{l}\text { Abatacept } \\
\text { n, II5 }\end{array}$ & $\begin{array}{l}\text { Placebo } \\
\text { n, I } 33\end{array}$ & $\begin{array}{l}\text { Abatacept } \\
n, 258\end{array}$ & $\begin{array}{l}\text { Placebo } \\
\text { n, } 219\end{array}$ & $\begin{array}{l}\text { Abatacept } \\
n, 433\end{array}$ & $\begin{array}{l}\text { Placebo } \\
n, 418\end{array}$ & $\begin{array}{l}\text { Abatacept } \\
n, 856\end{array}$ \\
\hline Total AEs & - & - & 71.4 & 79.5 & 84.0 & 87.3 & 86.1 & 89.7 \\
\hline URI & 7.6 & 11.3 & 7.5 & 5.8 & 9.6 & 10.9 & - & - \\
\hline Headache & 15.1 & 14.8 & 5.3 & 12.4 & 11.9 & 17.6 & 13.9 & 20.3 \\
\hline Discontinuation due to AEs & 9.2 & 5.2 & 3.8 & 3.5 & 1.8 & 4.2 & 4.3 & 5.0 \\
\hline SAEs & 16.0 & 12.2 & 11.3 & 10.5 & 11.9 & 15.0 & 12.2 & 11.7 \\
\hline Malignancies & 2.5 & 3.5 & - & - & 0.9 & 0.9 & 3.8 & 3.2 \\
\hline Infections & - & - & 2.3 & 2.3 & 2.3 & 3.9 & 1.7 & 2.6 \\
\hline Respiratory disorders/cough & 2.5 & 5.2 & 0 & 1.2 & 0.5 & 1.6 & 1.2 & I.I \\
\hline Peri-infusional reactions & - & - & - & - & 16.9 & 24.5 & 20.3 & 24.3 \\
\hline Acute infusional reactions & - & - & 3.0 & 5.0 & 4.1 & 8.8 & 7.1 & 10.0 \\
\hline Deaths & 0 & 0 & 0 & 0.4 & 0.5 & 0.2 & 1.0 & 0.6 \\
\hline
\end{tabular}

Notes: Data presented include only patients treated with abatacept $\sim 10 \mathrm{mg} / \mathrm{kg}$ vs placebo during the trial's double-blind period. Trials with combinations of biologics were not included since this is not used in practice. All values are percentages (\%).

a 2 -month data.

b6-month data.

I 2-month data only for patients receiving background nonbiologic DMARDs (except infusion reactions, which includes all patients)

Abbreviations: $A E$, adverse event; $S A E$, serious adverse event; URI, upper respiratory tract infection.

of zero after a year ( $8 \%$ of placebo, $p=0.05)$. As was seen in the 6-month data, abatacept was well-tolerated with adverse event rates in both dosing groups similar to placebo.

\section{AIM}

The 12-month phase III trial, Abatacept in Inadequate responders to Methotrexate (AIM), was published by Kremer et al in $2006 .{ }^{62}$ In this double-blind study, 652 patients who had active RA despite at least 3 months of MTX at a dose of $15 \mathrm{mg} /$ week or greater were randomly assigned to receive abatacept $10 \mathrm{mg} / \mathrm{kg}$ or placebo iv every 4 weeks. All patients were also treated with a stable dose of at least MTX $15 \mathrm{mg} / \mathrm{wk}$. Between 6 and 12 months, investigators blinded to the treatment group could adjust the dose of MTX, add an additional DMARD, or adjust the prednisone dose up to $10 \mathrm{mg}$ /day as deemed necessary. The primary objective measures were to evaluate, 1) the ACR 20 response at 6 months, 2) the HAQ-DI improvement of $\geq 0.3$ at 12 months, and 3) the Genant-modified Sharp score at 12 months.

At 6 months, the proportion of patients with an ACR 20 response was significantly higher in the abatacept group (67.9\% vs $39.7 \%)$. The 12 -month data are listed in Table 2. A post-hoc analysis revealed that the proportion achieving ACR 50 and 70 responses was statistically significantly higher at 12 months than at 6 , suggesting that some patients obtained additional benefit even after 6 months. At 6 and 12 months, $14.8 \%$ and $23.8 \%$, respectively, of patients treated with abatacept were in remission (DAS28 < 2.6) compared with $2.8 \%$ and $1.9 \%$ who received placebo.

Baseline and 12-month radiographic data were available for $92 \%$ of the study population. Abatacept-treated patients had significant slowing of radiographic damage, which was approximately $50 \%$ of that reported in the placebo group. The mean change from baseline in erosion score, mean jointspace narrowing score, and the total Genant-modified Sharp score for the abatacept and placebo groups were 0.63 vs 1.14 , 0.58 vs 1.18 , and 1.21 vs 2.32 , respectively. The authors note that the amount of progression was rather low and the clinical significance of this degree of change is uncertain and requires long-term observation. A total of $56 \%$ of patients on abatacept had no progression compared with $45 \%$ in the placebo group. ${ }^{63}$

The proportion of patients having a clinically important gain in physical function (HAQ-DI) was greater after receiving 12 months of abatacept ( $63.7 \%$ vs $39.3 \%, \mathrm{p}<0.001)$. Significant improvements in health-related quality of life (SF-36) were also reported at both 6 and 12 months. All eight physical and mental subscores from the SF-36 showed significantly greater improvements from baseline in the abatacept but not placebo group.

More patients treated with abatacept discontinued therapy because of adverse events (AEs), but the percentages were low (4.8\% vs $1.8 \%)$ (Table 3$)$. Acute and peri-infusional adverse events were more common in the abatacept group 
(8.8\% and $24.5 \%$ compared with $4.1 \%$ and $16.9 \%$ in the placebo group, respectively), and 2 of these patients had severe reactions. Prespecified serious infections were infrequent, occurring in $2.5 \%$ in the treatment arm and $0.9 \%$ in the control group. Bronchopulmonary aspergillosis developed in a patient in the active treatment arm, and 1 case of unconfirmed tuberculosis (TB) was reported in each group. Neoplasms developed in $0.9 \%$ of patients in each group with a large B cell lymphoma of the thyroid developing in a patient on abatacept and endometrial carcinoma while on placebo.

\section{AIM 2-year extension study}

The results from the open-label, 12-month extension study were published by Kremer et al in $2008 .{ }^{64}$ Of the 547 patients completing the first year of the AIM study, 539 entered the open-label extension and received abatacept $10 \mathrm{mg} / \mathrm{kg}$ iv every 4 weeks. The efficacy and safety analyses included all patients who received at least 1 dose of abatacept. ACR responses after 2 years were similar regardless of whether patients were initially randomized to placebo or abatacept for the first 12 months. As was observed with ACR 50 and 70 responses between months 6 and 12, the proportion of patients attaining a low disease activity state (LDAS) and remission was greater at 24 months than at 12 months (LDAS: $56.1 \%$ vs $44.1 \%$; remission: $30.9 \%$ vs $25.4 \%$, respectively).

HAQ-DI and SF-36 benefits were maintained throughout the second year. Improvements in sleep and fatigue were also noted with abatacept. Fatigue scores, measured on a 100-point visual analog scale, dropped by approximately 30 points (a 10-point decrease is felt to be clinical meaningful). Interestingly, those who began active treatment at 12 months eventually attained improvements in physical function, quality of life, sleep, and fatigue comparable to the original abatacept group treated for a full 2 years.

Two-year X-ray data were available from $87 \%$ of patients enrolled in the extension study and $72 \%$ of all patients involved in the initial randomization. ${ }^{63}$ The progression rate in the total Genant-modified Sharp score in the group who received 2 years of abatacept was reduced by an additional $57 \%$ during the second year (0.46) compared with the first (1.07). After 2 years, the total score increased 1.55 units from baseline in this group, whereas the group who received a year of placebo followed by 1 year of abatacept saw an increase of 3.17 units. A benefit was noted in both erosion and joint space narrowing scores. Only $21 \%$ of patients who had no progression at 1-year progressed during the second year in the abatacept arm. Of the patients randomized to abatacept who did show radiographic progression during the first year, $45 \%$ had no further progression during the second. Finally, $53 \%$ of the original placebo arm who had progressed at 1 year had no progression after being given abatacept for the next year.

The types and rates of AEs were similar among the first and second years of treatment with abatacept. ${ }^{64}$ The serious infection rate held stable at approximately 4 per 100 patient-years. The percentage of patients who discontinued abatacept at some point within the double-blind and extension periods due to AEs, serious AEs (SAEs), and infections were $6.4 \%, 4.0 \%$, and $1.2 \%$, respectively. Basal cell skin cancer developed in 6 patients and 2 patients each developed lung cancer and lymphoma. The paper did not differentiate between the original 2 groups when reporting the 2 -year safety data since all had received abatacept by that point.

\section{ATTEST}

The results from Abatacept or infliximab vs placebo, a Trial for Tolerability, Efficacy and Safety in Treating rheumatoid arthritis (ATTEST) were reported by Schiff et al in 2008. ${ }^{65}$ Patients without prior biologic DMARD exposure who had active disease despite at least 3 months of MTX $15 \mathrm{mg} /$ week were randomized in a 3:3:2 ratio to abatacept $10 \mathrm{mg} / \mathrm{kg}$ every 4 weeks, infliximab $3 \mathrm{mg} / \mathrm{kg}$ every 8 weeks, or placebo in a double-blind, double-dummy fashion for 6 months. At 6 months patients randomized to receive placebo were given abatacept for the remaining 6 months of the study. After 6 months, other oral DMARDs could be added and MTX and glucocorticoid doses could be adjusted. The dose of infliximab could not be escalated to maintain or increase efficacy, which would be common in clinical practice.

The primary outcome was the reduction in DAS28 with abatacept compared with placebo at 6 months. There were numerous secondary and even tertiary outcomes, some of which compared the efficacy and safety of abatacept with infliximab. It is important to remember, however, that this study was not powered to compare the 2 active treatment arms with regards to superiority or non-inferiority.

A total of 431 patients were randomized and treated (Table 1). The reduction in DAS28 at day 197 was significantly greater with abatacept vs placebo $(-2.53$ vs -1.48 , $\mathrm{p}<0.001)$. Figures 1 and 2 present the clinical efficacy data at 6 and 12 months. After 197 days, ACR response and remission rates were similar in the abatacept and infliximab 


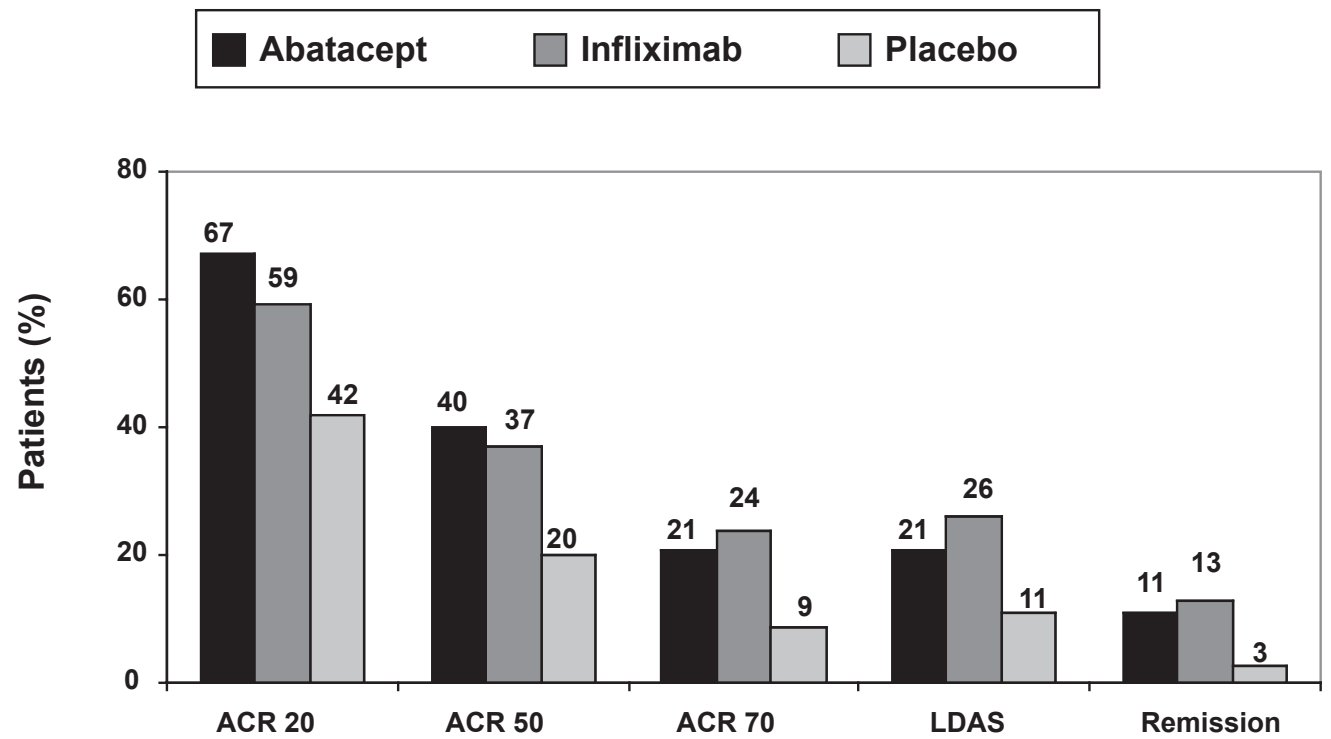

Figure I Efficacy of abatacept and infliximab at 6 months after inadequate responses to MTX (ATTEST).

Notes: All patients received concomitant methotrexate.

Abatacept vs placebo: $p<0.001$ for ACR 20 and 50 and $p=0.019$ for ACR 70 response rates.

Infliximab vs placebo: $p=0.006$ for $A C R 20, p=0.004$ for $A C R 50$, and $p=0.002$ for $A C R 70$ response rates.

Abbreviations: ACR, American College of Rheumatology; LDAS, low disease activity score (DAS28 $<3.2$ ); Remission, DAS28 $<2.6$.

groups, which were significantly greater than placebo. At one year, however, patients treated with abatacept achieved further gains while the response rates in the infliximab group remained stable compared with the 6 month results. All of the clinical outcomes were numerically greater with abatacept, however, for each of these comparisons the 95\% CI were wide and overlapped in all but the ACR 20 and LDAS rates.

After 6 months, both treatment arms experienced statistically significant improvements from baseline compared

\section{Abatacept $\square$ Infliximab}

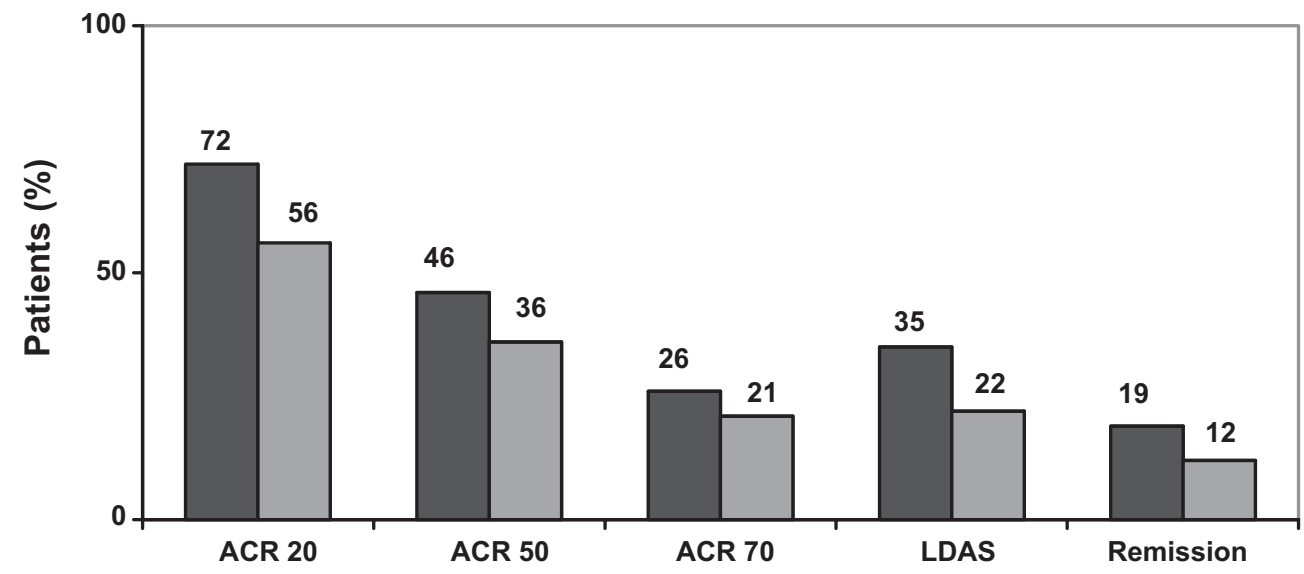

Figure 2 Efficacy of abatacept and infliximab at 12 months after inadequate responses to MTX (ATTEST).

Notes: All patients received concomitant methotrexate.

ACR 20 response rate, estimate of difference $=16.7(95 \% \mathrm{Cl}=5.5,27.8)$.

ACR 50 response rate, estimate of difference $=9.1(95 \% \mathrm{Cl}=-2.2,20.5)$.

ACR 70 response rate, estimate of difference $=5.7(95 \% \mathrm{Cl}=-4.2,15.6)$.

LDAS rate, estimate of difference $=12.9(95 \% \mathrm{Cl}=2.1,23.7)$.

Remission rate, estimate of difference $=6.5(95 \% \mathrm{Cl}=-2.2,15.2)$.

Abbreviations: ACR, American College of Rheumatology; LDAS, low disease activity score (DAS28 < 3.2); Remission, DAS28 $<2.6$; Cl, confidence interval. 
with placebo in all 8 subscales of the SF-36. After 1 year, however, abatacept showed a greater improvement than infliximab in the physical component of health-related quality of life. The mental component and all 8 subscales were numerically greater with abatacept versus infliximab. The percentage of patients demonstrating a clinically meaningful improvement in physical function (HAQ-DI) was similar in the 2 groups at 6 and 12 months.

Over the first 6 months the rates of AEs were surprisingly low in the abatacept group, in some measures even lower than the placebo group (Table 4). Safety data at the end of 12 months were not reported for the initial placebo group even though they received abatacept from months 6 to 12 . The 12-month safety data therefore compares the original abatacept and infliximab groups. The percentage of patients who developed SAEs, discontinuation due to SAEs and AEs, serious infections, and acute infusional events were all greater in the infliximab group than the abatacept group.

\section{Abatacept efficacy and safety after an inadequate response to TNFIs ATTAIN}

Published by Genovese et al in 2005, the Abatacept Trial in Treatment of Anti-TNF Inadequate Responders (ATTAIN) was a 6-month, double-blind study that enrolled patients with active RA despite at least 3 months of infliximab and/ or etanercept who were also receiving an oral DMARD. ${ }^{66}$ After a washout period (28 days for etanercept and 60 days for infliximab), baseline measurements were obtained from 391 patients who were then randomized in a $2: 1$ ratio to receive abatacept $10 \mathrm{mg} / \mathrm{kg}$ or placebo every 4 weeks. The background nonbiologic DMARDs were continued. The 2 primary endpoints were the proportion of patients with an
ACR 20 response and the proportion with a HAQ improvement of at least 0.3 from baseline.

The rates of ACR 20 response rates were significantly higher in the abatacept group beginning at day 15 and progressively increased throughout the 6 months of the trial (Figure 3). Significantly more patients in the abatacept group had a clinically important improvement in the HAQ from baseline (47.3\% vs $23.3 \%$, p $<0.001)$. Significant improvements in health-related quality of life were also evident after 6 months of abatacept. ${ }^{67}$ There was a negative relationship between baseline DAS28 scores and improvement in quality of life with treatment. Those patients who began with high disease activity obtained less improvement than those with low disease activity at baseline.

The rates of AEs were similar among the groups (Table 3), with $10.5 \%$ and $11.3 \%$ developing SAEs in the abatacept and placebo groups, respectively. Only $3.5 \%$ of patients treated with abatacept and $3.8 \%$ in the placebo group withdrew from the study due to AEs. None of the infusion reactions were felt to be severe.

\section{ATTAIN 2-year extension study}

Two-year efficacy and safety data were reported by Genovese et al in $2008 .^{68}$ An 18-month open-label, extension study was performed and included 317 of the 322 patients that completed the 6-month double-blind period $(84.5 \%$ and $74.4 \%$ of the patients initially randomized to receive abatacept and placebo, respectively). All patients were treated with abatacept $10 \mathrm{mg} / \mathrm{kg}$ every 4 weeks in combination with background DMARDs with adjustments permitted based upon the discretion of the clinician. A total of 222 of the 317 patients $(70 \%)$ were still participating in the study after the 18-month extension.

Table 4 Adverse events of abatacept and infliximab (ATTEST)

\begin{tabular}{|c|c|c|c|c|c|}
\hline \multirow[t]{2}{*}{ Adverse events } & \multicolumn{2}{|l|}{ Abatacept } & \multicolumn{2}{|l|}{ Infliximab } & \multirow{2}{*}{$\begin{array}{l}\text { Placebo } \\
\text { (6 months) }\end{array}$} \\
\hline & 6 months & 12 months & 6 months & 12 months & \\
\hline Total AEs & 82.7 & 89.1 & 84.8 & 93.3 & 83.6 \\
\hline Discontinuation due to AEs & 1.9 & 3.2 & 4.8 & 7.3 & 0.9 \\
\hline Acute infusional events & 5.1 & 7.1 & 18.2 & 24.8 & 10.0 \\
\hline SAEs & 5.1 & 9.6 & 11.5 & 18.2 & 11.8 \\
\hline Serious infections & 1.3 & 1.9 & 4.2 & 8.5 & 2.7 \\
\hline Malignancies & 0.6 & 0.6 & 1.2 & 1.2 & 0.9 \\
\hline Discontinuation due to SAEs & 1.3 & 2.6 & 2.4 & 3.6 & 0 \\
\hline Deaths & 0.6 & 0.6 & 0.6 & 1.2 & 0 \\
\hline
\end{tabular}

Notes: All values are percentages (\%).

Abbreviations: $\mathrm{AE}$, adverse event; $\mathrm{SAE}$, serious adverse event. 


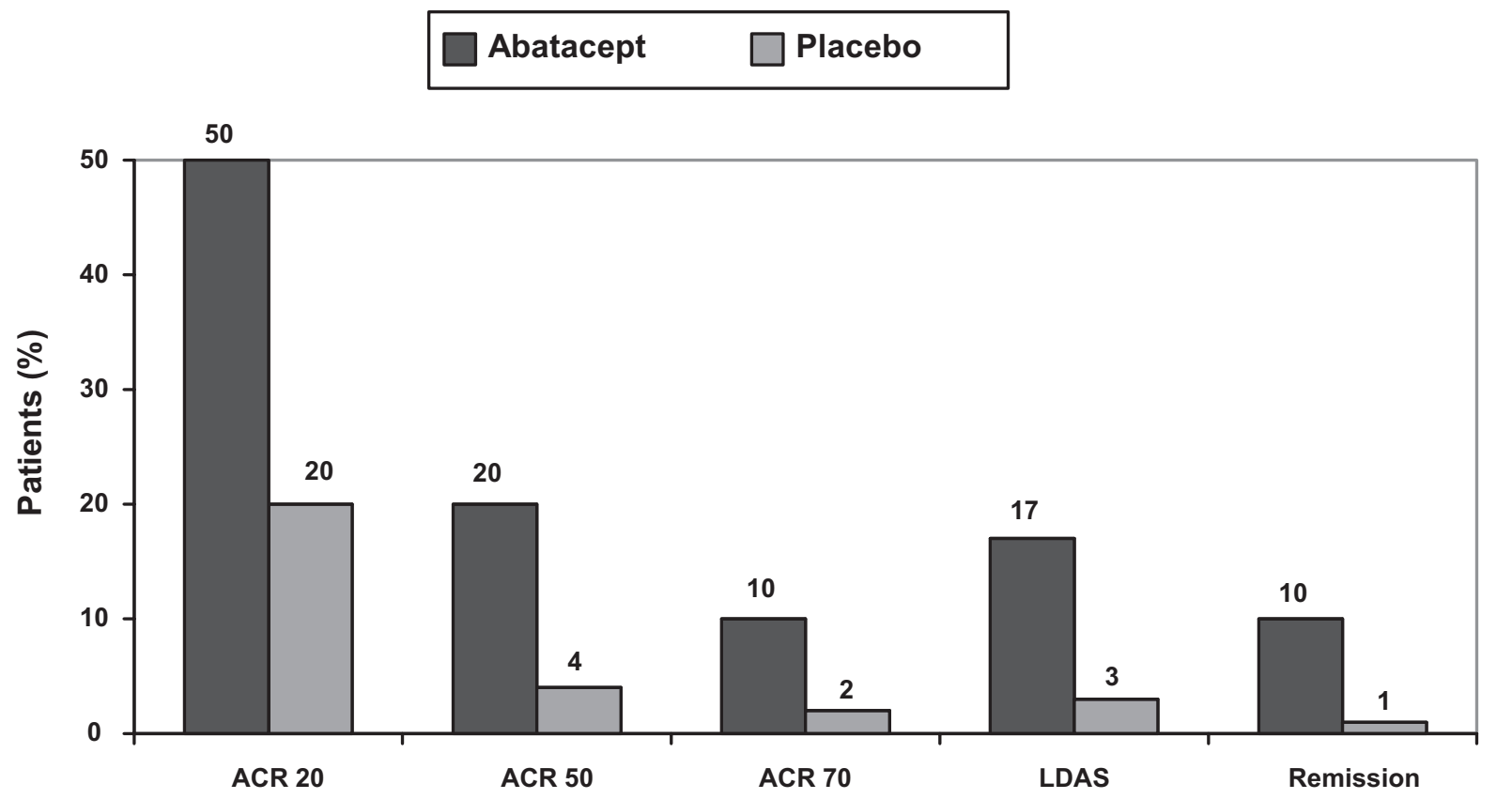

Figure 3 Efficacy of abatacept at 6-months after inadequate responses to TNFIs (ATTAIN).

Notes: All patients received concomitant nonbiologic DMARDs (MTX $75 \%-80 \%$, sulfasalazine $7 \%-10 \%$, hydroxychloroquine $9 \%$, leflunomide $8 \%$ to $9 \%$ ). $p<0.00$ I for all comparisons except the ACR 70 response rate, with $p=0.003$.

Abbreviations: TNFI, tumor necrosis factor inhibitor; ACR, American College of Rheumatology; LDAS, low disease activity score (DAS28 $<3.2$ ); Remission, DAS28 $<2.6$.

The ACR 20, 50, and 70 responses after 2 years were comparable regardless of whether patients were initially randomized to receive abatacept or placebo $(56.2 \%$ vs $51.5 \%$, $33.2 \%$ vs $32.3 \%$, and $16.1 \%$ vs $13.1 \%$, respectively). The mean change in DAS28 from baseline, which was -1.99 after 6 months, further improved to -2.66 by 24 months. The improvements in quality of life and physical function seen in the abatacept group at 6 months persisted throughout the longterm extension study. Those patients given placebo initially but who received abatacept for the final 18 months obtained clinically meaningful SF-36 and HAQ-DI responses as well.

The frequency of AEs and SAEs was similar to those reported at 6 months. Twenty-five patients (7\%) developed serious infections at a rate of 5 per 100 patient-years. There were no unexpected opportunistic infections. The reported malignancies included 5 non-melanomatous skin cancers, 2 cases of thyroid cancer/neoplasm, as well as a case each of T-cell lymphoma, breast cancer, ovarian cancer, prostate cancer, and uterine cancer.

\section{ASSURE}

Weinblatt et al reported the results from the Abatacept Study of Safety in Use with other RA Therapies (ASSURE) in $2006 .{ }^{69}$ Enrolled patients had RA that was active enough to warrant additional therapy as judged by the investigator despite 3 months of treatment with biologic and/or nonbiologic DMARDs. Those who were eligible were randomized in a 2:1 fashion to receive either abatacept $10 \mathrm{mg} / \mathrm{kg}$ or placebo as an iv infusion every 4 weeks for 1 year in addition to the background DMARDs already being taken. After the initial 12-month double-blind period, patients were allowed to enter an open-label extension during which all patients received abatacept $10 \mathrm{mg} / \mathrm{kg}$ every month. During the first 3 months, dosage adjustments of the concomitant background agents were only allowed in cases of toxicity. Beyond 3 months, however, biologic and nonbiologic DMARDs could be stopped, added, or undergo dosage changes.

The primary objective was to evaluate the safety of the addition of abatacept to background agents and specifically included patients with comorbid conditions in the analysis (stable congestive heart failure (CHF), asthma, chronic obstructive pulmonary disease (COPD), and diabetes). Exploratory secondary outcomes included the HAQ-DI, as well as visual analogue scale (VAS) scores of patient's global assessment of disease activity, patient's global assessment of pain, and physician's global assessment of disease activity.

A total of 1441 patients received at least one infusion, and $87 \%$ and $82 \%$ of the abatacept and placebo arms, respectively, completed the study (Table 1). Approximately $7 \%$ of 
the study population had diabetes, $6 \%$ had asthma, $4 \%$ had COPD, and $1 \%$ to $2 \%$ had CHF. At the time of randomization 167 patients were receiving biological DMARDs and accounted for $10.7 \%$ and $13.3 \%$ of the abatacept and placebo groups, respectively. Etanercept was the baseline biologic agent for nearly two-thirds of this subgroup, with infliximab, adalimumab, and anakinra each accounting for about $10 \%$ to $20 \%$ of the remainder.

The mean changes from baseline in patient- and physicianreported outcomes were significantly better in the groups receiving abatacept. Similarly, abatacept treatment resulted in greater mean changes in physical function (HAQ-DI). Although this trial was not designed to compare efficacy between groups, post hoc analyses revealed that the group receiving abatacept with nonbiologic DMARDs had greater improvements than the subgroup receiving combination biologic therapy.

The overall incidences of AEs were similar in the groups not treated with the combination biologic regimen (Table 5). In the patients on a background of nonbiologic DMARDs, the subgroup taking leflunomide in addition to abatacept $(12 \%$ to $14 \%$ of the nonbiologic population), was reported to have a higher frequency of SAEs $(23.6 \%$ vs $15.3 \%)$. There was no apparent trend in the specific type of AE noted. Importantly, the subgroup receiving combination biologic therapy discontinued therapy due to AEs and SAEs more frequently and developed a greater percentage of SAEs, serious infections, neoplasms (Table 5). Lung cancer developed in 3 patients treated with abatacept compared with none in the placebo group.

The analysis of comorbid conditions revealed that patients with COPD who received abatacept had higher rates of respiratory system AEs (43.2\% vs $23.5 \%$ ) and SAEs (27\% vs $5.9 \%$ ). The AE rates were similar among the diabetic and nondiabetic populations but could not be assessed in the CHF and asthma populations due to low numbers of patients.

\section{Phase Ilb trial with combination therapy}

The results from a IIb trial designed to evaluate the efficacy of the combination of abatacept and etanercept were published by Weinblatt et al in 2007. Eligible patients must have had at least 8 swollen joints and at least 10 tender joints despite at least 3 months of etanercept $25 \mathrm{mg}$, twice weekly. During the initial double-blind 6-month period, patients were randomized in a $2: 1$ ratio to receive abatacept $2 \mathrm{mg} / \mathrm{kg}$ (note the lower dose) or placebo every 4 weeks in addition to etanercept $25 \mathrm{mg}$ twice weekly. Stable doses of prednisone under $10 \mathrm{mg}$ per day were allowed, but all other DMARDs were discontinued before randomization. After 6 months oral DMARDs and prednisone (up to $10 \mathrm{mg}$ per day) could be added and changed at the discretion of the investigator.

The primary outcome was an ACR 20 response after 6 months, which was modified to exclude CRP due to difficulty enrolling patients with elevated CRP levels while on etanercept. At the end of 1 year, patients could then enroll in an open-label long-term extension study in which all patients received abatacept $10 \mathrm{mg} / \mathrm{kg}$ (note the typical dosing) in addition to etanercept.

A total of 121 patients were randomized, but only 80 $(66 \%)$ completed the double-blind period. Those who discontinued treatment due to inefficacy were considered nonresponders, and those who withdrew due to other reasons had their last observations carried forward. The baseline characteristics were similar among the 2 groups with an average disease duration of approximately 13 years (Table 1 ).

At 6 months, modified ACR 20 and 50 response rates were not significantly different among abatacept + etanerceptand placebo + etanercept-treated patients $(48.2 \%$ vs $30.6 \%$, $\mathrm{p}=0.072$ and $25.9 \%$ vs $19.4 \%, \mathrm{p}=0.448$, respectively), but patients on combination therapy were more likely to achieve modified ACR 70 responses $(10.6 \%$ vs $0 \%, p=0.042)$. All ACR responses after 1 year were comparable between the groups, however.

Table 5 Adverse events with abatacept plus biologic or nonbiologic DMARDs (ASSURE)

\begin{tabular}{lllll}
\hline Adverse event & $\begin{array}{l}\text { Abatacept + biologic } \\
\text { DMARD background }\end{array}$ & $\begin{array}{l}\text { Abatacept + nonbiologic } \\
\text { DMARD background }\end{array}$ & $\begin{array}{l}\text { Placebo + biologic } \\
\text { DMARD background }\end{array}$ & $\begin{array}{l}\text { Placebo + nonbiologic } \\
\text { DMARD background }\end{array}$ \\
\hline Total AEs & 95.1 & 89.7 & 89.1 & 86.1 \\
Discontinuation due to AEs & 8.7 & 5.0 & 3.1 & 4.3 \\
SAEs & 22.3 & 11.7 & 12.5 & 12.2 \\
Total neoplasms & 6.8 & 3.2 & 1.6 & 3.8 \\
Infections & 5.8 & 2.6 & 1.6 & 1.7 \\
Discontinuation due to SAEs & 4.9 & 2.1 & 3.1 & 1.2
\end{tabular}

Notes: All values are percentages (\%).

Abbreviations: AE, adverse event; SAE, serious adverse event; DMARD, disease-modifying antirheumatic drug. 
All 80 of the patients completing the double-blind period entered the long-term extension portion of the study and received abatacept $10 \mathrm{mg} / \mathrm{kg}$ in addition to etanercept. Less than 30 patients from each group continued this combination for an additional 2 years, however. The modified ACR 20,50 , and 70 response rates were numerically higher at the end of the first year of the open-label extension when all patients were taking abatacept $10 \mathrm{mg} / \mathrm{kg}$ and etanercept compared with the ACR responses at the end of the initial double-blind period. Low numbers of patients made the analysis after the third year difficult, but the ACR responses seemed to be maintained.

At 1 year, the group treated with combination therapy had higher frequencies of AEs, SAEs, and discontinuations due to AEs (Table 6). The long-term extension period revealed similar rates of AEs, highlighted by the high number of "respiratory, thoracic, and mediastinal disorders" and 10\% of patients stopping therapy due to AEs.

The low dose of abatacept used during the double-blind period of this study may have played a role in the lackluster efficacy results. Additionally, due to a shortage of etanercept, the initial patient enrollment had to be cut short and reduced the statistical power of the study. That being said, this study showed limited clinical efficacy as well as a worrisome increase in SAEs when treating patients with the combination of abatacept and etanercept.

\section{Abatacept efficacy and safety without prior MTX or TNFI exposure AGREE}

The previous trials enrolled patients with long-standing RA (mean disease duration 7-13 years). Recently, Westhovens et al conducted the first study of abatacept in patients with early RA. ${ }^{12}$ Abatacept study to Gauge Remission and joint damage progression in MTX naïve patients with Early Erosive RA (AGREE) is a 2-year, double-blind study that enrolled patients with less than 2 years of disease without MTX exposure ( $\leq 10 \mathrm{mg} /$ week for $\leq 3$ ). All patients had to be seropositive (RF and/or anti-CCP2 antibodies) and have evidence of erosive disease within the hands, wrists, or feet. Eligible patients were randomized to receive placebo plus MTX (increased up to $20 \mathrm{mg} / \mathrm{wk}$ ) or abatacept $10 \mathrm{mg} / \mathrm{kg}$ plus MTX for 12-months before an open-label 12 month extension. The co-primary endpoints of the study were remission (DAS28 < 2.6) and Genant-modified Sharp total score.

The study population of 509 patients was predominantly South American (40.3\%) and European (36.0\%) and had a mean disease duration of 6.5 months (Table 1). A statistically significant difference in remission rates was found by day 57 , and after 1 year $41.4 \%$ of abatacept-treated patients were in remission compared with $23.3 \%$ in the placebo group (Figure 4). The change from baseline in total Genant-modified Sharp scores and erosion scores were significantly lower for abatacept, while minimal joint space narrowing progression was noted in both groups. The proportion of patients with no radiographic progression was $61.2 \%$ and $52.9 \%$ in the abatacept and placebo-treated patients, respectively (difference $8.3 \%, 95 \% \mathrm{CI}-1.0,17.5$ ). A total of $71.9 \%$ of abatacept-treated patients had clinically important increases in the HAQ-DI compared with $62.1 \%$ in the placebo arm $(p=0.024)$. Significantly greater improvements in both the physical and mental components of the SF-36 were also found after treatment with abatacept versus placebo.

Table 6 Adverse events with the combination of abatacept and etanercept (phase llb)

\begin{tabular}{llll}
\hline Adverse event & $\begin{array}{l}\text { Abatacept } \mathbf{~ m g / k g}+\text { etanercept } \\
\text { (first I 2 months) }\end{array}$ & $\begin{array}{l}\text { Placebo + etanercept } \\
\text { (first I 2 months) }\end{array}$ & $\begin{array}{l}\text { Abatacept I0 mg/kg + etanercept } \\
\text { (LTE) }\end{array}$ \\
\hline Total AEs & 92.9 & 88.9 & 97.5 \\
URI & 23.5 & 13.9 & 28.8 \\
Sinusitis & 16.5 & 8.3 & 22.5 \\
Discontinuation due to AEs & 11.8 & 2.8 & 10 \\
SAEs & 16.5 & 2.8 & 32.5 \\
Malignancies & 0 & 1.2 & 3.8 \\
Infections & 3.5 & 0 & 1.3 \\
Respiratory disorders & 35.3 & 9.4 & 40 \\
Deaths & 0 & 0 & 1.3 \\
\hline
\end{tabular}

Notes: All values are percentages (\%).

Abbreviations: LTE, long-term extension; AE, adverse event; SAE, serious adverse event; URI, upper respiratory tract infection. 


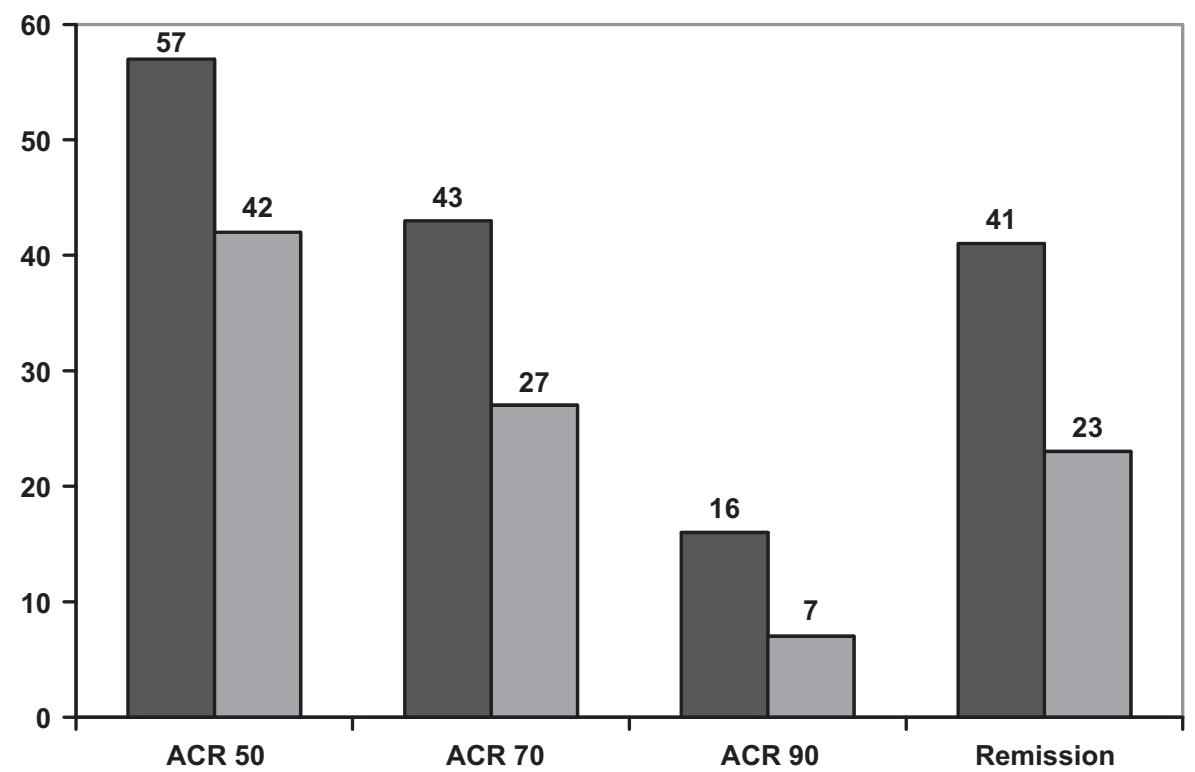

Figure 4 Efficacy of abatacept in methotrexate-naïve patients (AGREE).

Notes: All patients received concomitant methotrexate.

$P<0.001$ for ACR 50 and 70 responses, and remission rates.

$\mathrm{P}=0.001$ for ACR 90 .

Abbreviations: ACR, American College of Rheumatology; Remission, DAS28 $<2.6$.

Adverse events were comparable between the abatacept and placebo arms with SAEs, serious infections, and discontinuations due to SAEs occurring in $7.8 \%$ vs $7.9 \%$, $2.0 \%$ vs $2.0 \%$, and $1.2 \%$ vs $1.2 \%$, respectively. Acute infusional events were more common with abatacept (6.3\% vs $2.0 \%$ ). All were graded as mild to moderate intensity with the exception of one case of severe urticaria. The only malignancy reported was a case of pancreatic cancer in a patient being treated with abatacept.

\section{Abatacept safety and tolerability Common reactions}

The most common adverse reactions reported in the controlled trials were headaches, upper respiratory tract infections, nasopharyngitis, nausea, and infusion reactions (Table 3). Often the rates were similar to that seen with placebo. Anaphylaxis or anaphylactoid reactions were reported in only 2 of 2688 patients in the clinical trials. ${ }^{46}$ Hypersensitivity reactions involving hypotension, urticaria, and dyspnea were rare, with each occurring in less than $0.9 \%$ of patients. ${ }^{46}$ In ATTEST, there was a higher rate of infusion reactions in those receiving infliximab than abatacept (Table 4).

\section{Infections}

In the placebo-controlled trials, $54 \%$ of abatacept-treated patients developed infections compared with $48 \%$ treated with placebo. ${ }^{46}$ The vast majority of these were upper respiratory tract infections, sinusitis, urinary tract infections, and bronchitis. With regards to serious infections, an analysis of 4150 patients treated for over 10,000 person-years during the double-blind periods from 8 clinical trials reported rates of hospitalization for infection at 3.05 per 100 person-years for abatacept and 2.15 per 100 person-years for placebo. ${ }^{70}$ The incidence rate appears to be stable over time and does not increase with increasing exposure to abatacept. A metaanalysis of 5 abatacept trials involving 1960 patients did not find an increased risk of serious infections with a pooled odds ratio of 1.35 (95\% CI $0.78,2.32){ }^{71}$

Patients with COPD appear to be especially prone to developing AEs. The package insert specifically recommends using caution when considering abatacept in a patient with COPD. ${ }^{46}$ Most studies in RA do not report safety results for individual comorbidities, however this was part of the primary outcome of interest in ASSURE. ${ }^{69}$ Of the 37 COPD patients enrolled in the trial, $43.2 \%$ of those treated with abatacept experienced AEs involving the respiratory system, 
compared with $23.5 \%$ receiving placebo. The overall rates of infections were similar among the groups, but SAEs were more common with abatacept (27\% vs 5.9\%). Over $10 \%$ of abatacept-treated patients developed SAEs involving the respiratory tract compared with none on placebo.

A major concern with the TNFIs has been the potential for opportunistic infections, especially with regards to the reactivation of latent tuberculosis (TB). While it is recommended that a tuberculin skin test (TST) is placed prior to starting abatacept, ${ }^{72}$ to date, TB reactivation has not been an issue. In the controlled trials listed above, all patients were screened with a TST prior to enrolling. Only 2 patients developed TB during the double-blind periods, with an abatacept-treated patient having a lymph node being "compatible with possible TB" and another in the placebo arm with "unconfirmed TB". ${ }^{62}$ The rate of TB is estimated at approximately 0.06 cases per 100 person-years, mostly accounted for by patients from areas where TB is endemic. ${ }^{70}$ Furthermore, in a mouse model of chronic TB infection, abatacept at doses of approximately $20 \mathrm{mg} / \mathrm{kg}$ did not impair the ability of mice to control the infection. ${ }^{73}$ Abatacept-treated mice showed no difference in mycobacterial burden, histological features, or the numbers of $\mathrm{CD}^{+}, \mathrm{CD}^{+}$, or activated $\mathrm{T}$ cells, whereas all of the mice treated with a TNF antibody died within 9 weeks.

\section{Malignancy}

Compared with multiple external RA cohorts, similar rates of malignancy were reported for abatacept-treated patients after $>10,000$ patient-years of exposure. ${ }^{74}$ The incidence rate for malignancy, excluding non-melanomatous skin cancers, is 0.71 cases per 100 patient-years, which is similar to the selected RA cohorts. During the double-blind period of the trials lung cancers were diagnosed more often in the abatacept arms. The cumulative exposure data estimated an incidence of 0.16 per 100 patient-years. A total of 17 cases were observed, which is within the expected range (9 to 26) based upon the external RA cohorts. In ASSURE, 3 cases of lung cancer developed, with 2 occurring in smokers within 100 days of starting abatacept. ${ }^{69}$ The lymphoma rate is greater than the general population but is also reported to be within the expected range for an RA population, whereas colorectal and breast cancers were observed less frequently than what would be expected. ${ }^{74}$

\section{Tolerability}

Overall, abatacept $10 \mathrm{mg} / \mathrm{kg}$ was very well tolerated in the clinical trials with a retention rate of $87 \%$ through the first year of treatment compared to $79 \%$ with placebo. ${ }^{61,62,65,69}$
Discontinuation rates due to AEs are approximately $6 \%$ for abatacept and $4 \%$ for placebo. ${ }^{46}$

\section{Immunogenicity and immunizations}

Biologic agents have the potential to be immunogenic, ${ }^{75-77}$ which possibly account for efficacy and safety differences. Although studies have reported conflicting data, ${ }^{78-81}$ a potential mechanism for the loss of efficacy in patients on the TNFIs involves the development of antibodies against a portion of the drug. Many patients also develop ANA and/or dsDNA positivity while on TNFIs, though most do not have clinical features of a lupus-like syndrome. Because of this, the immunogenicity of abatacept and rates of autoimmune symptoms and disorders have been followed closely in most of the trials.

The maker of abatacept published data on the drug's immunogenicity after studying serum samples from 2237 patients involved in the phase II and III trials. ${ }^{82}$ Depending upon the sensitivity of the assay used, approximately $3 \%$ of patients demonstrated an antibody response to either the whole abatacept molecule (2.1\%) or to the CTLA-4 portion $(1.0 \%)$. The package insert quotes a $1.7 \%$ incidence of antibody formation in clinical trials. ${ }^{46}$ In the phase III trials patients who discontinued therapy were more likely to have developed antibodies compared with those who did not discontinue therapy ( $7.4 \%$ vs $2.6 \%$, respectively) although there was no clear association with reduced efficacy or increased AEs. The small number of antibody-positive patients limited the analysis. Contrary to what has been shown in the trials with the TNF inhibitors, the development of antibodies was not prevented with the concomitant administration of MTX and no patients on abatacept monotherapy demonstrated immunogenicity.

An abstract from the 2008 ACR meeting from the maker of abatacept reported an analysis of "autoimmune" AEs. ${ }^{83}$ A total of 4150 patients were exposed to abatacept with mean exposure of 30.4 months (10,365 total person-years). A total of 161 autoimmune AEs were reported (1.59 per 100 patientyears). Psoriasis was the most commonly reported, with a rate of 0.53 per 100 patient-years during the double-blind period of the clinical trials compared with no patients receiving placebo. The rate did not increase with increasing exposure, and in the majority of cases psoriasis was a pre-existing condition that flared rather than developed during the trial. The analysis of cumulative abatacept exposure revealed low rates of Sjögren's syndrome ( 0.19 per 100 patient-years), SLE ( 0.05 per 100 patient-years), and a lupus-like syndrome (0.01 per 100 patient-years). A single case of MS was reported, but 
this was felt to be a pre-existing condition and unrelated to abatacept. In ATTEST, the development of anti-nuclear or anti-DNA antibodies after 1 year of treatment in patients who tested negative at baseline was 6.5 and $2.4 \%$, respectively, with abatacept and 47.7 and $47.7 \%$ with infliximab. ${ }^{84}$ This finding did not translate into an increased rate of autoimmune events for either group, however.

The affect of abatacept on the antibody response to immunizations is uncertain. In a murine model, CTLA4Ig administration blocked the antibody response to a soluble protein neoantigen, especially when given within 2 days of the immunization. ${ }^{85}$ Responses to secondary immunization were also suppressed although not to the degree seen with the primary immunization. Administration of the 23 -valent pneumococcal and tetanus toxoid vaccines to healthy volunteers 2 weeks after receiving a single dose of abatacept resulted in decreased antibody titers, although at least $60 \%$ still had a positive response to tetanus and over $70 \%$ responded to at least 3 pneumococcal serotypes ${ }^{86}$ Lower percentages were reported from 21 patients in the Abatacept Researched in Rheumatoid arthritis patients with an Inadequate anti-TNF response to Validate Effectiveness (ARRIVE) trial with $81 \%$ mounting a response to at least 1 serotype and $48 \%$ to 3 or more. ${ }^{87}$ These patients were also treated with MTX, which has been associated with lower response rates to pneumococcal vaccination. ${ }^{88,89}$ Finally, another subanalysis of 20 patients from ARRIVE who had been on abatacept for at least 3 months examined whether trivalent influenza vaccination 7 days prior to a dose of abatacept led to fourfold increase in antibody titers relative to baseline. ${ }^{90}$ A total of 15 patients $(75 \%)$ had positive responses to at least 1 strain and $50 \%$ responded to 2 or 3 strains.

Overall, the immunogenicity of abatacept appears to be low. Whether the development of antibodies directed against the whole molecule or against the CTLA-4 portion result in efficacy, tolerability, or safety issues remains to be confirmed. Abatacept likely has an effect on the antibody response to immunization, but it is not clear at this time whether this translates into a clinically significant reduction in protection rates. The Centers for Disease Control and Prevention recommend consideration of pneumococcal and influenza vaccinations for patients with chronic illnesses as well as those who are immunosuppressed..$^{91}$ The ACR has published similar recommendations for RA patients on biologic DMARDs. ${ }^{72}$

\section{Abatacept in the management of RA}

This is an exciting time in the management of RA, with multiple DMARDs available for use and many new biologic agents being developed and studied. The prospect of reaching a state of disease remission is now possible. However, many patients will have inadequate responses to the currently approved therapies. Abatacept has filled a gap for many patients with contraindications to or inadequate responses with the TNFIs. Multiple randomized clinical trials have demonstrated clinical improvement for patients refractory to MTX and TNFIs as well as those with early RA who are MTX-naïve. This benefit is not only with ACR and DAS28 responses, but also patient-reported outcomes such as healthrelated quality of life and physical function. Trials involving patients refractory to MTX and MTX-naïve patients with early seropositive, erosive RA have reported slowed radiographic progression. While no head-to-head trials have been specifically designed and powered to compare abatacept with another available biologic agent, it appears to be a safe and effective alternative. In the ATTEST study, which was not powered to detect a difference between the 2 active treatment arms but was randomized and blinded, abatacept was at least as efficacious as low-dose infliximab after 1 year and appeared to be better tolerated.

As with the other biologic DMARDs, the cost of abatacept is much greater than that of MTX. Based upon a model assuming many variables, the cost-effectiveness of abatacept in patients with inadequate responses to MTX (AIM) was estimated to be US\$47,910 per qualityadjusted life-year (QALY) gained over a 10-year period, and US\$43,041 per QALY over a lifetime. ${ }^{92}$ For those with inadequate responses to TNFIs (ATTAIN) 10-year and lifetime estimates are US\$50,576 and US\$45,979 per QALY gained, respectively. ${ }^{93}$ Each study assumed that those who do not respond to abatacept would be managed only on nonbiologic DMARDs, not alternative biologic agents. These cost estimates are comparable with those reported with infliximab and etanercept. ${ }^{92}$

As opposed to infliximab and rituximab, abatacept is FDA-approved for use with or without concomitant nonbiologic DMARDs (the EMEA requires concomitant MTX). Studies involving the TNFIs, however, have shown that outcomes are improved when used in combination with MTX rather than as monotherapy. ${ }^{9,94}$ Similar trials have not been performed with abatacept. In fact, with the exception of the pilot study, all of the clinical trials used MTX in combination with abatacept in the active treatment arms (ATTAIN required a background DMARD, which was MTX in $75 \%$ to $80 \%$ of patients). The addition of MTX for patients on abatacept should be strongly considered unless there is a contraindication or intolerance. 
Although there is variability among patients, clinical experience has shown that the time to response is probably longer after starting abatacept than after starting a TNFI. ATTEST did seem to support this, although the difference was not dramatic (10\% to $15 \%$ more ACR 20 responders with infliximab at months 1 and 2 but no difference by month 3 ). ${ }^{65}$ Response rates have been reported to continue to increase over time, up to 2 years in some patients. The abatacepttreated patients in ATTEST were more likely to achieve good EULAR responses and remission after 12 months compared with 6 months.$^{65}$ In AIM the clinical signs and symptoms continued to improve over the treatment course, with greater ACR responses at 12 months than at 6 months and higher remission rates at 24 months than 12 months. ${ }^{62,64}$ However, if "no meaningful improvement" is noted after 16 weeks of abatacept, a consensus group has recommended re-evaluation of its continued use. ${ }^{95}$

The clinical significance of delaying abatacept for 12 months in the AIM trial and having an increase of 1.62 units in the total Genant-modified Sharp score after 2 years is uncertain. Either way, it is encouraging that HAQ and SF-36 scores are comparable after 2 years regardless of the initial treatment group, suggesting that function is not lost to an appreciable degree by delaying abatacept in patients with long-standing RA who have had inadequate responses to MTX. Extended follow-up will help clarify if the difference in radiographic progression continues or increases and eventually results in a clinically important loss of function. The results from the second year of the AGREE trial will address whether the same is true for patients with early seropositive, erosive RA or if these patients are best managed with early abatacept.

Due to the apparent additive toxicity in the studies combining abatacept with a TNFI, ${ }^{69,96}$ the optimal timing regarding the initiation of abatacept after a TNFI is uncertain. In ATTAIN, which enrolled patients with prior exposure to the anti-TNF agents, all patients underwent a wash-out period before receiving abatacept. A subanalysis from ARRIVE showed similar safety regardless of whether patients waited 2 months before starting abatacept or simply started it when the next TNFI dose was scheduled to be given. ${ }^{97}$ Although this study did not differentiate among the different TNFIs, it does provide some reassurance that abatacept can be given safely soon after switching agents and a consensus group has issued recommendations supporting this. ${ }^{95}$ Patients undergoing a transition among biologic agents should be monitored closely for signs of infection, however.

Table 7 Risk and benefit summary for patients considering abatacept

Benefits (placebo in parentheses)

ACR 20, 50, 70 response rates in established RA after MTX, 63\%-73\%, 42\%-48\%, 21\%-29\% (35\%-40\%, 18\%-20\%, 6\%-8\%)

Remission rates in established RA after MTX, 20\%-35\% (2\%-10\%)

ACR 20, 50,70 response rates in established RA after TNFI, $50 \%, 20 \%, 10 \%(20 \%, 4 \%, 2 \%)$

Remission rates in established RA after TNFI, $10 \%(1 \%)$

ACR 50, 70, 90 response rates in early RA, 57.4, 42.6, $16.4 \%(42.3,27.3,6.7 \%)$

Remission rates in early RA, $41.4 \%$ (23.3\%)

Improves function and quality of life in established and early RA

Slows radiographic progression in established and early RA

Risks

Common AEs: headache, upper respiratory tract infection, nasopharyngitis, dizziness, nausea, infusion reaction

SAEs: serious infections $3 \%(2 \%)$, malignancy I.3\% (I.1\%), more lung cancer and lymphoma cases (see article text), severe infusion reactions $<1 \%$

\section{Warnings and precautions \\ COPD}

Latent TB (reactivation reported with the TNFIs)

HBV (reactivation reported with other biologic DMARDs)

Frequent infections

No live vaccines within 3 months of a dose

Pre-treatment assessment

Tuberculin skin testing

HBV screening

Influenza and pneumococcal vaccinations

Abbreviations: ACR, American College of Rheumatology; RA, rheumatoid arthritis; MTX, methotrexate; TNFI, tumor necrosis factor inhibitor; LDAS, low disease activity state; $A E$, adverse event; $\mathrm{SAE}$, serious adverse event; COPD, chronic obstructive pulmonary disease; TB, tuberculosis; HBV, hepatitis B virus; DMARD, disease-modifying antirheumatic drug. 
Where abatacept fits into the management of RA must be taken on a case-by-case basis and incorporates the comfort of the patient and treating rheumatologist with its dosing and safety profiles (Table 7). Studies have not been done to identify particular patients who may have better outcomes with abatacept or a TNFI as the initial biologic agent. We also have no data from controlled trials to guide the decision regarding the best agent to use after a TNFI. Abatacept has been approved in the US for use as a first-line biologic agent after an inadequate response to a nonbiologic DMARD; however, many rheumatologists would still use the TNFIs initially and reserve abatacept for subsequent inadequate responses or intolerance. ${ }^{26,34}$ At this point the TNFIs have a much longer track record, which is reassuring for both efficacy and safety. However, the very low rates of immunogenicity, serious infections, opportunistic infections, and infusion reactions with abatacept are encouraging. The ability to self-administer abatacept subcutaneously is currently being studied and, assuming similar efficacy, would likely make it a more attractive option for use as an initial or second biologic agent. Continued surveillance and postmarketing studies will provide a clearer understanding of the risk to benefit ratio of abatacept and enable us to better define its role in the management of RA.

\section{Disclosures}

The author declares no conflicts of interest.

\section{References}

1. Helmick CG, Felson DT, Lawrence RC, et al. Estimates of the prevalence of arthritis and other rheumatic conditions in the United States. Part I. Arthritis Rheum. 2008;58(1):15-25.

2. Lee DM, Weinblatt ME. Rheumatoid arthritis. Lancet. 2001; 358(9285): 903-911.

3. Sokka T, Krishnan E, Hakkinen A, Hannonen P. Functional disability in rheumatoid arthritis patients compared with a community population in Finland. Arthritis Rheum. 2003;48(1):59-63.

4. Goekoop-Ruiterman YP, de Vries-Bouwstra JK, Allaart CF, et al. Clinical and radiographic outcomes of four different treatment strategies in patients with early rheumatoid arthritis (the BeSt study): a randomized, controlled trial. Arthritis Rheum. 2005;52(11):3381-3390.

5. Goekoop-Ruiterman YP, de Vries-Bouwstra JK, Allaart CF, et al. Comparison of treatment strategies in early rheumatoid arthritis: a randomized trial. Ann Intern Med. 2007;146(6):406-415.

6. Combe B, Landewe R, Lukas C, et al. EULAR recommendations for the management of early arthritis: report of a task force of the European Standing Committee for International Clinical Studies Including Therapeutics (ESCISIT). Ann Rheum Dis. 2007;66(1):34-45.

7. Anderson JJ, Wells G, Verhoeven AC, Felson DT. Factors predicting response to treatment in rheumatoid arthritis: the importance of disease duration. Arthritis Rheum. 2000;43(1):22-29.

8. Mottonen T, Hannonen P, Korpela M, et al. Delay to institution of therapy and induction of remission using single-drug or combinationdisease-modifying antirheumatic drug therapy in early rheumatoid arthritis. Arthritis Rheum. 2002;46(4):894-898.
9. Breedveld FC, Weisman MH, Kavanaugh AF, et al. The PREMIER study: A multicenter, randomized, double-blind clinical trial of combination therapy with adalimumab plus methotrexate versus methotrexate alone or adalimumab alone in patients with early, aggressive rheumatoid arthritis who had not had previous methotrexate treatment. Arthritis Rheum. 2006;54(1):26-37.

10. Emery P, Breedveld FC, Hall S, et al. Clinical remission, radiographic non-progression, and normalized function with the combination of etanercept and methotrexate in the treatment of early active rheumatoid arthritis: 1-year results of the COMET trial [abstract 1208]. Arthritis Rheum. 2008;58(9 Suppl):S617.

11. St Clair EW, van der Heijde DM, Smolen JS, et al. Combination of infliximab and methotrexate therapy for early rheumatoid arthritis: a randomized, controlled trial. Arthritis Rheum. 2004;50(11): 3432-3443.

12. Westhovens R, Robles M, Ximenes AC, et al. Clinical efficacy and safety of abatacept in methotrexate-naïve patients with early rheumatoid arthritis and poor prognostic factors. Ann Rheum Dis. 2008; Epub 2009 Jan 5. doi:10.1136/ard.2008.101121.

13. Braun J, Kastner P, Flaxenberg P, et al. Comparison of the clinical efficacy and safety of subcutaneous versus oral administration of methotrexate in patients with active rheumatoid arthritis: results of a six-month, multicenter, randomized, double-blind, controlled, phase IV trial. Arthritis Rheum. 2008;58(1):73-81.

14. O'Dell JR, Haire CE, Erikson N, et al. Treatment of rheumatoid arthritis with methotrexate alone, sulfasalazine and hydroxychloroquine, or a combination of all three medications. $N$ Engl J Med. 1996;334(20):1287-1291.

15. O'Dell JR, Leff R, Paulsen G, et al. Treatment of rheumatoid arthritis with methotrexate and hydroxychloroquine, methotrexate and sulfasalazine, or a combination of the three medications: results of a two-year, randomized, double-blind, placebo-controlled trial. Arthritis Rheum. 2002;46(5):1164-1170.

16. Svensson B, Boonen A, Albertsson K, van der Heijde D, Keller C, Hafstrom I. Low-dose prednisolone in addition to the initial diseasemodifying antirheumatic drug in patients with early active rheumatoid arthritis reduces joint destruction and increases the remission rate: a two-year randomized trial. Arthritis Rheum. 2005;52(11): 3360-3370.

17. Landewe RB, Boers M, Verhoeven AC, et al. COBRA combination therapy in patients with early rheumatoid arthritis: long-term structural benefits of a brief intervention. Arthritis Rheum. 2002;46(2): 347-356.

18. Strand V, Cohen S, Schiff M, et al. Treatment of active rheumatoid arthritis with leflunomide compared with placebo and methotrexate. Leflunomide Rheumatoid Arthritis Investigators Group. Arch Intern Med. 1999;159(21):2542-2550.

19. Kremer JM, Genovese MC, Cannon GW, et al. Concomitant leflunomide therapy in patients with active rheumatoid arthritis despite stable doses of methotrexate. A randomized, doubleblind, placebo-controlled trial. Ann Intern Med. 2002;137(9): 726-733.

20. Choy EH, Panayi GS. Cytokine pathways and joint inflammation in rheumatoid arthritis. N Engl J Med. 2001;344(12):907-916.

21. Bresnihan B, Alvaro-Gracia JM, Cobby M, et al. Treatment of rheumatoid arthritis with recombinant human interleukin-1 receptor antagonist. Arthritis Rheum. 1998;41(12):2196-2204.

22. Cohen S, Hurd E, Cush J, et al. Treatment of rheumatoid arthritis with anakinra, a recombinant human interleukin-1 receptor antagonist, in combination with methotrexate: results of a twenty-four-week, multicenter, randomized, double-blind, placebo-controlled trial. Arthritis Rheum. 2002;46(3):614-624.

23. Cohen SB, Moreland LW, Cush JJ, et al. A multicentre, double blind, randomised, placebo controlled trial of anakinra (Kineret), a recombinant interleukin 1 receptor antagonist, in patients with rheumatoid arthritis treated with background methotrexate. Ann Rheum Dis. 2004; 63(9):1062-1068. 
24. Nuki G, Bresnihan B, Bear MB, McCabe D. Long-term safety and maintenance of clinical improvement following treatment with anakinra (recombinant human interleukin-1 receptor antagonist) in patients with rheumatoid arthritis: extension phase of a randomized, double-blind, placebo-controlled trial. Arthritis Rheum. 2002;46(11):2838-2846.

25. Mertens M, Singh JA. Anakinra for rheumatoid arthritis. Cochrane Database of Systematic Reviews. 2009; Issue 1. Art. No.: CD005121. DOI: 10.1002/14651858.CD005121.pub3.

26. Klareskog L, Catrina AI, Paget S. Rheumatoid arthritis. Lancet. Epub 2009 Jan 20. DOI:10.1016/S0140-6736(09)60008-8.

27. Keystone EC, Kavanaugh AF, Sharp JT, et al. Radiographic, clinical, and functional outcomes of treatment with adalimumab (a human anti-tumor necrosis factor monoclonal antibody) in patients with active rheumatoid arthritis receiving concomitant methotrexate therapy: a randomized, placebo-controlled, 52-week trial. Arthritis Rheum. 2004; 50(5):1400-1411.

28. Lipsky PE, van der Heijde DM, St Clair EW, et al. Infliximab and methotrexate in the treatment of rheumatoid arthritis. Anti-Tumor Necrosis Factor Trial in Rheumatoid Arthritis with Concomitant Therapy Study Group. N Engl J Med. 2000;343(22):1594-1602.

29. Moreland LW, Schiff MH, Baumgartner SW, et al. Etanercept therapy in rheumatoid arthritis. A randomized, controlled trial. Ann Intern Med. 1999;130(6):478-486.

30. Weinblatt ME, Kremer JM, Bankhurst AD, et al. A trial of etanercept, a recombinant tumor necrosis factor receptor:Fc fusion protein, in patients with rheumatoid arthritis receiving methotrexate. $N$ Engl J Med. 1999; 340(4):253-259

31. Ostergaard M, Unkerskov J, Linde L, et al. Low remission rates but long drug survival in rheumatoid arthritis patients treated with infliximab or etanercept: results from the nationwide Danish DANBIO database. Scand J Rheumatol. 2007;36(2):151-154.

32. Hjardem E, Ostergaard M, Podenphant J, et al. Do rheumatoid arthritis patients in clinical practice benefit from switching from infliximab to a second tumor necrosis factor alpha inhibitor? Ann Rheum Dis. 2007; 66(9):1184-1189.

33. Smolen JS, Aletaha D, Koeller M, Weisman MH, Emery P. New therapies for treatment of rheumatoid arthritis. Lancet. 2007;370(9602): 1861-1874.

34. Lutt JR, Deodhar A. Rheumatoid arthritis: strategies in the management of patients showing an inadequate response to TNFalpha antagonists. Drugs. 2008;68(5):591-606.

35. Cohen SB, Emery P, Greenwald MW, et al. Rituximab for rheumatoid arthritis refractory to anti-tumor necrosis factor therapy: Results of a multicenter, randomized, double-blind, placebo-controlled, phase III trial evaluating primary efficacy and safety at twenty-four weeks. Arthritis Rheum. 2006;54(9):2793-2806.

36. Edwards JC, Szczepanski L, Szechinski J, et al. Efficacy of B-celltargeted therapy with rituximab in patients with rheumatoid arthritis. N Engl J Med. 2004;350(25):2572-2581.

37. Emery P, Fleischmann R, Filipowicz-Sosnowska A, et al. The efficacy and safety of rituximab in patients with active rheumatoid arthritis despite methotrexate treatment: results of a phase IIB randomized, double-blind, placebo-controlled, dose-ranging trial. Arthritis Rheum. 2006;54(5):1390-1400.

38. Keystone EC, Emery P, Peterfy CG, et al. Rituximab inhibits structural joint damage in rheumatoid arthritis patients with an inadequate response to tumour necrosis factor inhibitor therapies. Ann Rheum Dis. 2009;68(2):216-221.

39. Mueller DL, Jenkins MK, Schwartz RH. Clonal expansion versus functional clonal inactivation: a costimulatory signalling pathway determines the outcome of T cell antigen receptor occupancy. Annu Rev Immunol. 1989;7:445-480.

40. Davis PM, Nadler SG, Stetsko DK, Suchard SJ. Abatacept modulates human dendritic cell-stimulated T-cell proliferation and effector function independent of IDO induction. Clin Immunol. 2008;126(1): $38-47$.
41. Kliwinski C, Kukral D, Postelnek J, et al. Prophylactic administration of abatacept prevents disease and bone destruction in a rat model of collagen-induced arthritis. J Autoimmun. 2005;25(3):165-171.

42. Finck BK, Linsley PS, Wofsy D. Treatment of murine lupus with CTLA4Ig. Science. 1994;265(5176):1225-1227.

43. Lin H, Bolling SF, Linsley PS, et al. Long-term acceptance of major histocompatibility complex mismatched cardiac allografts induced by CTLA4Ig plus donor-specific transfusion. J Exp Med. 1993; 178(5):1801-1806.

44. Ruperto N, Lovell DJ, Quartier P, et al. Abatacept in children with juvenile idiopathic arthritis: a randomised, double-blind, placebocontrolled withdrawal trial. Lancet. 2008;372(9636):383-391.

45. Abatacept (Orencia) for rheumatoid arthritis. Med Lett Drugs Ther. 2006;48(1229):17-18.

46. Orencia [package insert]. Princeton NB-MSC.

47. Reynolds J, Shojania K, Marra CA. Abatacept: a novel treatment for moderate-to-severe rheumatoid arthritis. Pharmacotherapy. 2007; 27(12):1693-1701.

48. Felson DT, Anderson JJ, Boers M, et al. The American College of Rheumatology preliminary core set of disease activity measures for rheumatoid arthritis clinical trials. The Committee on Outcome Measures in Rheumatoid Arthritis Clinical Trials. Arthritis Rheum. 1993;36(6):729-740.

49. Felson DT, Anderson JJ, Boers M, et al. American College of Rheumatology. Preliminary definition of improvement in rheumatoid arthritis. Arthritis Rheum. 1995;38(6):727-735.

50. Fransen J, Creemers MC, Van Riel PL. Remission in rheumatoid arthritis: agreement of the disease activity score (DAS28) with the ARA preliminary remission criteria. Rheumatology (Oxford). 2004; 43(10):1252-1255.

51. Prevoo ML, van 't Hof MA, Kuper HH, van Leeuwen MA, van de Putte LB, van Riel PL. Modified disease activity scores that include twenty-eight-joint counts. Development and validation in a prospective longitudinal study of patients with rheumatoid arthritis. Arthritis Rheum. 1995;38(1):44-48.

52. Vrijhoef HJ, Diederiks JP, Spreeuwenberg C, Van der Linden S. Applying low disease activity criteria using the DAS28 to assess stability in patients with rheumatoid arthritis. Ann Rheum Dis. 2003; 62(5):419-422.

53. Genant HK. Methods of assessing radiographic change in rheumatoid arthritis. Am J Med. 1983;75(6A):35-47.

54. Genant HK, Jiang Y, Peterfy C, Lu Y, Redei J, Countryman PJ. Assessment of rheumatoid arthritis using a modified scoring method on digitized and original radiographs. Arthritis Rheum. 1998; 41(9): $1583-1590$

55. Ware JE Jr, Sherbourne CD. The MOS 36-item short-form health survey (SF-36). I. Conceptual framework and item selection. Med Care. 1992;30(6):473-483.

56. Samsa G, Edelman D, Rothman ML, Williams GR, Lipscomb J, Matchar D. Determining clinically important differences in health status measures: a general approach with illustration to the Health Utilities Index Mark II. Pharmacoeconomics. 1999;15(2): 141-155.

57. Kosinski M, Zhao SZ, Dedhiya S, Osterhaus JT, Ware JE Jr. Determining minimally important changes in generic and diseasespecific health-related quality of life questionnaires in clinical trials of rheumatoid arthritis. Arthritis Rheum. 2000; 43(7): $1478-1487$.

58. Wells GA, Tugwell P, Kraag GR, Baker PR, Groh J, Redelmeier DA. Minimum important difference between patients with rheumatoid arthritis: the patient's perspective. J Rheumatol. 1993;20(3): $557-560$.

59. Moreland LW, Alten R, Van den Bosch F, et al. Costimulatory blockade in patients with rheumatoid arthritis: a pilot, dose-finding, double-blind, placebo-controlled clinical trial evaluating CTLA-4Ig and LEA29Y eighty-five days after the first infusion. Arthritis Rheum. 2002;46(6):1470-1479. 
60. Kremer JM, Westhovens R, Leon M, et al. Treatment of rheumatoid arthritis by selective inhibition of T-cell activation with fusion protein CTLA4Ig. N Engl J Med. 2003;349(20):1907-1915.

61. Kremer JM, Dougados M, Emery P, et al. Treatment of rheumatoid arthritis with the selective costimulation modulator abatacept: twelvemonth results of a phase iib, double-blind, randomized, placebocontrolled trial. Arthritis Rheum. 2005; 52(8):2263-2271.

62. Kremer JM, Genant HK, Moreland LW, et al. Effects of abatacept in patients with methotrexate-resistant active rheumatoid arthritis: a randomized trial. Ann Intern Med. 2006;144(12):865-876.

63. Genant HK, Peterfy CG, Westhovens R, et al. Abatacept inhibits progression of structural damage in rheumatoid arthritis: results from the long-term extension of the AIM trial. Ann Rheum Dis. 2008;67(8):1084-1089.

64. Kremer JM, Genant HK, Moreland LW, et al. Results of a two-year followup study of patients with rheumatoid arthritis who received a combination of abatacept and methotrexate. Arthritis Rheum. 2008; 58(4):953-963.

65. Schiff M, Keiserman M, Codding C, et al. Efficacy and safety of abatacept or infliximab vs placebo in ATTEST: a phase III, multi-centre, randomised, double-blind, placebo-controlled study in patients with rheumatoid arthritis and an inadequate response to methotrexate. Ann Rheum Dis. 2008;67(8):1096-1103.

66. Genovese MC, Becker JC, Schiff M, et al. Abatacept for rheumatoid arthritis refractory to tumor necrosis factor alpha inhibition. $N$ Engl $J$ Med. 2005;353(11):1114-1123.

67. Westhovens R, Cole JC, Li T, et al. Improved health-related quality of life for rheumatoid arthritis patients treated with abatacept who have inadequate response to anti-TNF therapy in a double-blind, placebocontrolled, multicentre randomized clinical trial. Rheumatology (Oxford). 2006;45(10):1238-1246.

68. Genovese MC, Schiff M, Luggen M, et al. Efficacy and safety of the selective co-stimulation modulator abatacept following 2 years of treatment in patients with rheumatoid arthritis and an inadequate response to anti-tumour necrosis factor therapy. Ann Rheum Dis. 2008; 67(4):547-554.

69. Weinblatt M, Combe B, Covucci A, Aranda R, Becker JC, Keystone E. Safety of the selective costimulation modulator abatacept in rheumatoid arthritis patients receiving background biologic and nonbiologic disease-modifying antirheumatic drugs: A one-year randomized, placebo-controlled study. Arthritis Rheum. 2006; 54(9):2807-2816.

70. Smitten A, Simon T, Qi K, et al. Hospitalized infections in the abatacept RA clinical development program: an epidemiological assessment with $>10,000$ person-years of exposure [abstract 1674]. Arthritis Rheum. 2008;58(9 Suppl):S786.

71. Salliot C, Dougados M, Gossec L. Risk of serious infections during rituximab, abatacept and anakinra treatments for rheumatoid arthritis: meta-analyses of randomised placebo-controlled trials. Ann Rheum Dis. 2009;68(1):25-32.

72. Saag KG, Teng GG, Patkar NM, et al. American College of Rheumatology 2008 recommendations for the use of nonbiologic and biologic disease-modifying antirheumatic drugs in rheumatoid arthritis. Arthritis Rheum. 2008;59(6):762-784.

73. Bigbee CL, Gonchoroff DG, Vratsanos G, Nadler SG, Haggerty HG, Flynn JL. Abatacept treatment does not exacerbate chronic Mycobacterium tuberculosis infection in mice. Arthritis Rheum. 2007; 56(8):2557-2565.

74. Smitten A, Simon T, Qi K, et al. Malignancies in the abatacept RA clinical development program: an updated epidemiological assessment with $>10,000$ person-years of exposure [abstract 1675]. Arthritis Rheum. 2008;58(9 Supp1):S787.

75. Charles PJ, Smeenk RJ, De Jong J, Feldmann M, Maini RN. Assessment of antibodies to double-stranded DNA induced in rheumatoid arthritis patients following treatment with infliximab, a monoclonal antibody to tumor necrosis factor alpha: findings in open-label and randomized placebo-controlled trials. Arthritis Rheum. 2000;43(11):2383-2390.
76. De Rycke L, Kruithof E, Van Damme N, et al. Antinuclear antibodies following infliximab treatment in patients with rheumatoid arthritis or spondylarthropathy. Arthritis Rheum. 2003;48(4):1015-1023.

77. Eriksson C, Engstrand S, Sundqvist KG, Rantapaa-Dahlqvist S. Autoantibody formation in patients with rheumatoid arthritis treated with anti-TNF alpha. Ann Rheum Dis. 2005;64(3):403-407.

78. Haraoui B, Cameron L, Ouellet M, White B. Anti-infliximab antibodies in patients with rheumatoid arthritis who require higher doses of infliximab to achieve or maintain a clinical response. J Rheumatol. 2006;33(1):31-36.

79. Maini RN, Breedveld FC, Kalden JR, et al. Sustained improvement over two years in physical function, structural damage, and signs and symptoms among patients with rheumatoid arthritis treated with infliximab and methotrexate. Arthritis Rheum. 2004;50(4): 1051-1065.

80. Wolbink GJ, Vis M, Lems W, et al. Development of antiinfliximab antibodies and relationship to clinical response in patients with rheumatoid arthritis. Arthritis Rheum. 2006;54(3):711-715.

81. Finckh A, Dudler J, Wermelinger F, Ciurea A, Gabay C, Bas S. Detection of anti-infliximab antibodies is of limited value to predict acquired drug resistance to infliximab in rheumatoid arthritis [abstract 1651]. Arthritis Rheum. 2008;58(9 Suppl):S777.

82. Haggerty HG, Abbott MA, Reilly TP, et al. Evaluation of immunogenicity of the $\mathrm{T}$ cell costimulation modulator abatacept in patients treated for rheumatoid arthritis. J Rheumatol. 2007;34(12): 2365-2373.

83. Smitten A, Oi K, Simon T, Becker JC. Autoimmune adverse events in the abatacept RA clinical development program: a safety analysis with $>10,000$ person-years of exposure [abstract 1673]. Arthritis Rheum. 2008;58(9 Suppl):S786

84. Schiff M, Keiserman M, Codding C, et al. Incidence of anti-nuclear and anti-DNA antibody seropositivity and immunogenicity in patients with rheumatoid arthritis treated with abatacept or infliximab [abstract SAT 0030]. Ann Rheum Dis. 2007;66(2 Suppl):437.

85. Linsley PS, Wallace PM, Johnson J, et al. Immunosuppression in vivo by a soluble form of the CTLA-4 T cell activation molecule. Science. 1992;257(5071):792-795.

86. Tay L, Leon F, Vratsanos G, Raymond R, Corbo M. Vaccination response to tetanus toxoid and 23-valent pneumococcal vaccines following administration of a single dose of abatacept: a randomized, open-label, parallel group study in healthy subjects. Arthritis Res Ther. 2007;9(2):R38.

87. Schiff M, Kaell A, Tay L, Vratsanos G, Bahrt K. Response to pneumococcal vaccine in rheumatoid arthritis patients with an inadequate response to anti-TNF therapy treated with abatacept in the ARRIVE trial [abstract SAT0029]. Ann Rheum Dis. 2007;66(2 Supp1):437.

88. Kapetanovic MC, Saxne T, Sjoholm A, Truedsson L, Jonsson G, Geborek P. Influence of methotrexate, TNF blockers and prednisolone on antibody responses to pneumococcal polysaccharide vaccine in patients with rheumatoid arthritis. Rheumatology (Oxford). 2006; 45(1):106-111.

89. Mease PJ, Ritchlin CT, Martin RW, et al. Pneumococcal vaccine response in psoriatic arthritis patients during treatment with etanercept. J Rheumatol. 2004;31(7):1356-1361.

90. Schiff M, Saewert M, Bahrt K, Genovese MC. Response to influenza vaccine in rheumatoid arthritis patients with an inadequate response to anti-TNF therapy treated with abatacept in the ARRIVE trial [abstract 943]. Arthritis Rheum. 2007;56(9 Suppl):S392.

91. cdc.gov [homepage on the internet]. Atlanta: Centers for Disease Control and Prevention [updated 2008 June 16; cited 2008 December 13]. Available from: http://www.cdc.gov/vaccines/specgrps/adults.htm.

92. Vera-Llonch M, Massarotti E, Wolfe F, et al. Cost-effectiveness of abatacept in patients with moderately to severely active rheumatoid arthritis and inadequate response to methotrexate. Rheumatology (Oxford). 2008;47(4):535-541. 
93. Vera-Llonch M, Massarotti E, Wolfe F, et al. Cost-effectiveness of abatacept in patients with moderately to severely active rheumatoid arthritis and inadequate response to tumor necrosis factor-alpha antagonists. J Rheumatol. 2008;35(9):1745-1753.

94. Klareskog L, van der Heijde D, de Jager JP, et al. Therapeutic effect of the combination of etanercept and methotrexate compared with each treatment alone in patients with rheumatoid arthritis: doubleblind randomised controlled trial. Lancet. 2004;363(9410):675-681.

95. Furst DE, Keystone EC, Kirkham B, et al. Updated consensus statement on biological agents for the treatment of rheumatic diseases, 2008. Ann Rheum Dis. 2008;67 Suppl 3:iii2-iii25.
96. Weinblatt M, Schiff M, Goldman A, et al. Selective costimulation modulation using abatacept in patients with active rheumatoid arthritis while receiving etanercept: a randomised clinical trial. Ann Rheum Dis. 2007;66(2):228-234.

97. Schiff MH, Pritchard C, Huffstutter JE, et al. The 6-month safety and efficacy of abatacept in patients with rheumatoid arthritis who underwent a washout after anti-TNF therapy or were directly switched to abatacept: the ARRIVE trial. Ann Rheum Dis. 2009; Epub 2008 Dec 15. doi:10.1136/ard.2008.099218.

\section{Publish your work in this journal}

Open Access Rheumatology Research and Reviews is an international, peer-reviewed, open access journal, publishing all aspects of clinica and experimental rheumatology in the clinic and laboratory including the following topics: Pathology, pathophysiology of rheumatologica diseases; Investigation, treatment and management of rheumatological diseases; Clinical trials and novel pharmacological approaches for the treatment of rheumatological disorders. The manuscript management system is completely online and includes a very quick and fair peerreview system, which is all easy to use. Visit http://www.dovepress.com/ testimonials.php to read real quotes from published authors.

Submit your manuscript here: http://www.dovepress.com/open-access-rheumatology-research-and-reviews-journal 